\title{
Journal of the Academy of Marketing Science 1973-2018: An Analytical Retrospective
}

\begin{abstract}
This paper analyses the entire publication history of the Journal of the Academy of Marketing Science (JAMS) by analyzing 1,747 documents from 1973 to June 2018. Citation networks were examined from available metadata such as author and index keywords, and institutional affiliations, and abstracts were analyzed using network analysis and text mining techniques. The analysis is supported by the use of data visualization tools and community detection algorithms. Results suggest three main communities addressed throughout JAMS' publication history (firm capability and performance, brand and value co-creation and customer service) and nine main themes (brands'strategic value, firms' strategy and financial performance, customer service, sales, marketing communications, retailing, distribution channel, global markets, and corporate social responsibility). Although empirical quantitative studies account the larger type of research published by $J A M S$, results also highlight $J A M S$ contribution to marketing theory building and methodological issues in the shape of both conceptual/theoretical papers and scale development papers.
\end{abstract}

Keywords: Journal of the Academy of Marketing Science, journal impact, citation analysis, bibliometric analysis, network analysis, text mining analysis 


\section{Introduction}

The Journal of the Academy of Marketing Science (JAMS) is said to be dedicated to the "study and improvement of marketing and serves as a vital link between scholarly research and practice by publishing research-based articles in the substantive domain of marketing" (JAMS, 2018). Since its inception in 1973, JAMS has been regarded as a key source of scholarly publications in the field of marketing providing a substantive impact on marketing practice. This has advanced the field of marketing generally and marketing science specifically. JAMS welcomes scholarly contributions that offer new insights and which demonstrate conceptual and methodological rigor. For the past 45 years, it has established itself as one of the most prestigious journals in the discipline of Marketing.

JAMS was ranked $31^{\text {st }}$ in the Financial Times top-50 journal list in 2017. It also currently enjoys the highest rank scores in at least three ranking agencies: The Association of Business Schools (4*-ranked) (best work in the field); the Australian Business Deans' Council (2016) (A*-ranked) and the Council for Evaluation of Research in Higher Education (A-ranked). Metrics available from 2017 are a measure of a journal's prestige. $J A M S^{\prime}$ ' $h$-index, article influence score, and impact factor-139, 2.335 and 8.488, respectively (Clarivate Analytics 2018; Scimago Lab, 2018)—are all indicative of the journal's relative position in the marketing science and general business, management and accounting discipline categories.

Our retrospective provides an opportunity to assess the journal's value and contribution to the Marketing community. This paper assesses this contribution through a detailed analysis using a combination of bibliometric/citation analysis, text mining analysis, network analysis and data visualization techniques. This allows an impartial assessment to be made of JAMS publications since 1973. To our knowledge this is the first such attempt made for any single journal in the Marketing discipline.

We aim to gain a better knowledge of the journal and its academic impact by answering the Research Questions (RQs) in Table 1.

Table 1. Research Questions.

\begin{tabular}{cl}
\hline Research interest & \multicolumn{1}{c}{ Research Questions (RQs) } \\
\hline Journal & $\begin{array}{l}\text { RQ1: Which are the main academic journals and academic fields } \\
\text { citing JAMS? }\end{array}$ \\
$\begin{array}{c}\text { Document typology } \\
\text { RQ2: In which type of documents do JAMS citations appear? } \\
\text { RQ3: Which countries (institutions and affiliation of } \\
\text { researchers) are citing and publishing in JAMS? }\end{array}$ \\
RQpics/Keywords & $\begin{array}{l}\text { RQ What topics do JAMS authors predominantly research } \\
\text { about, and which keywords are they using? }\end{array}$ \\
Ruthor & $\begin{array}{l}\text { RQ5: What is the authorship profile (average authors per article, } \\
\text { multiple authorship, etc.) in JAMS? }\end{array}$ \\
Author & RQ6: Who collaborates with whom in JAMS? \\
RQ7: Which are the main research communities in JAMS? \\
RQ8: Which are the main themes addressed by the papers \\
Themes & published in JAMS? \\
RQ9: Which are the main marketing constructs used in the \\
Constructs & papers published in JAMS?
\end{tabular}


Method/Data analysis RQ10: Which are the main methodological approaches and data techniques analysis techniques used in the papers published in JAMS?

By answering these RQs we aim to gain a better understating of the journal at different levels (individual, institutional, and country-based) in order to provide useful insights regarding:

- Impact of the journal (both at a journals and academic fields level)

- Relevant pieces of research (most cited) published in the journal

- Collaboration networks

- Main topics and research themes favored by the journal

- Main methodological approaches favored by the journal

- Main data analysis techniques favored by the journal

Our findings will have practical implications for different stakeholders of the journal including marketing theory and marketing history researchers, practitioners, and researchers interested in publishing in the journal. We also aim to methodologically contribute to the discipline of bibliometrics by showing how different bibliometric analysis techniques can be used for data triangulation and how they complement each other.

\section{Literature Review}

Few citation analyses have been made of the discipline of Marketing. Other discipline areas have received this treatment however. This includes our own work in the allied discipline areas of Operations Research (forthcoming) and the orthogonal discipline areas of Higher Education (Calma and Davies, 2015, 2017; Davies and Calma, 2016, 2017) and Philosophy (Davies and Calma, 2018). There is no reason to think that Marketing Science cannot be subject to, and benefit from, the same analyses however, and we provide precisely this below.

There have been some analyses of the Marketing discipline in general albeit they are limited in scope. A ranking of marketing journals using citation analysis was performed by Guidry et al (2004). They found that the key journals in the discipline of Marketing to be (in order of importance) Journal of Marketing Research, Journal of Marketing, Journal of Consumer Research and Marketing Science. A similar ranking exercise using Google Scholar's hg-index metric is provided in Touzani and Moussa (2010). They found the same four journals to be predominant but note a different order: Journal of Marketing, Journal of Consumer Research, Journal of Marketing Research, and Marketing Science. This 'core quartet' has been recognized by early researchers as the major journals in the field (Lehmann 2005; Seggie and Griffith 2009). As for $J A M S$, the journal has positioned itself among marketing academics as a top 5 journal (Hult et al. 1997, 2009; Luke and Doke 1987) elevating its standing to \#3 in the latest Thomson Reuters ranking (Clarivate Analytics 2018).

In terms of citation analyses of a specific area of Marketing, Samiee and Chadowski (2012) used exploratory factor analysis, hierarchical cluster analysis, and metric multidimensional scaling to assess bibliographic citations in the field of International Marketing over the period 1999-2010. Their work is certainly rigorous but limited to 10-years of analysis using articles from 34 representative academic journals in the field. In effect, it casts a wide net over the field rather than drills down using a whole-of-history approach. 
Of the single journals subject to bibliometric and citation analyses there are slim pickings. Little work has been done on Marketing Science specifically. One example is Tomas et al (2012) tribute to JAMS in its $40^{\text {th }}$ anniversary. Tomas and Hult (2015) analyzed citation data from $J A M S$ over a limited six-year period (2010-2015), and Malhotra (1996) attempted an analysis from 1987-1996. We know of no citation analysis of $J A M S$ over the entire lifecycle of its publication history. Indeed, we know of no longitudinal and synoptic analysis of a single key journal in the discipline of Marketing.

Our paper thus contributes to the discipline in two ways: 1. It extends previous work in citation analysis in the Marketing discipline; and 2. It provides an understanding of a single key journal in the field using source data from the entire history (46 volumes) of a journal, in this case, JAMS. This should be illuminating not only to JAMS readership but also to the broader marketing community. Our analysis provides an empirical basis for assessing the most published authors, the top contributing countries, the most represented universities, and other key concerns of the journal such as the main themes addressed, and research methods used. This enables substantive empirical conclusions to be drawn about the historical contribution of the journal to the field of Marketing science.

\section{Journal Rankings: A Caveat}

Journal rankings are here to stay. Perceptions about their value have always been mixed amongst scholars but it is not our intention in this paper to compare $J A M S$ with other journals in the Marketing field. Our focus is longitudinal (an entire history) and yet synoptic (a detailed analysis of the concerns of a particular journal, namely $J A M S$ ). Our intention is to include the comparative metrics associated with $J A M S$ to illustrate not only external validation of its position in the field but - as we discuss in more detail later-to show the extent of its impact. We provide this information at the beginning of the results section.

\section{Methods}

\section{Data and data collection}

A search was made in both Scopus and Web of Science on 25th June 2018 for all publications by $J A M S$ since its inception in 1973. Scopus provided more reliable data source, there being more than 600 articles missing in $W$ eb of Science which were indexed in Scopus. Hence, the Scopus data was extracted for analysis. This included 1,747 documents (1,574 articles, 90 reviews, 46 editorials and 37 articles in press), from 1973 through to an arbitrary cut-off point in 2018. The extracted data included all bibliometric metadata such as authors, titles, keywords, abstracts, affiliations, and references. We purposely excluded six errata, six short surveys, three notes and two letters as being unnecessary for our analytical survey. We found 654 of the 1,747 articles contained author keywords, (a total of 3,399 keywords). No index keywords were available for our analysis. Of the 1,747 articles, there were 1,619 with abstracts and 128 without. Author affiliations were recorded for 1,698 of the 1,747 articles.

\section{Data preparation and analysis}

The data extracted was converted into an Excel file for the purposes of analysis. Two analyses were performed: network analysis, including community detection using Kumu; and content analysis and text mining using $W$ ordStat. Kumu was used for analyses using 
abstracts, affiliations and keywords while WordStat was used for analyses involving abstracts. Excel was also used for data preparation and other analyses as outlined below.

The data was initially prepared for Kumu, a visualization tool for large data used for network analysis and diagrams such as those included in this paper. It incorporates both social network analysis and community detection, which makes possible the use of the Speaker-listener Label Propagation Algorithm (SLPA) algorithm in detecting overlapping communities. By contrast, WordStat detects word-based patterns in texts. Using keyword extraction - through text mining algorithms and frequency analysis-textual data as expressed in natural language can be labeled and analyzed by searching for similarities (cooccurrences) and anomalies among text documents (Kostoff, Toothman, Eberhart, \& Humenik, 2001). Therefore, text mining is used to overcome the limitations of data mining to handle huge amounts of unstructured textual documents (Yoon and Park 2004). Some of the features used in this study include text mining, visualization and hierarchical content analysis.

We combine both analyses in this paper to provide a comprehensive analysis of all usable metadata associated with every article published in JAMS since 1973 through to the date of search.

\section{Results and Discussion}

To begin, we provide a brief summary of the analysis that is available in Scopus. A quick overview of $J A M S$ publications reveals that customer satisfaction is the most popular keyword found in 31 articles and that the Texas A\&M University contributed the most articles to the journal with 68 papers. The United States is the highest contributor in terms of countries represented, and, in terms of authors, Dhruv Grewal and Christian Homburg contributed the most papers with 19 articles (including articles in press at the time of analysis). While these authors collaborated with others, Homburg has more articles where he appears as first author than Grewal.

\section{JAMS impact and the ten most cited articles}

The 1,747 papers in JAMS have attracted 63,221 citations to date, appearing in more than 150 journals across various disciplines. This equates to an average of nearly 43 citations per article. In order to answer RQ1 (Which are the main academic journals and academic fields citing $J A M S$ ?) we analyzed the main journals and academic fields citing $J A M S$. The key citations (in order) are from Journal of Business Research (1,788 papers), Industrial Marketing Management (1,131), JAMS (812), Journal of Business Ethics (745) and Journal of Retailing and Consumer Services (712) - together representing about $8 \%$ of the total number of citations. As expected, these citations have been represented primarily across business, management and accounting subject areas—at least 7 out of 10 papers, in fact—but they have also been popular in discipline areas such as the social sciences, economics, econometrics, finance, computer science, engineering, decision sciences, psychology and others. Regarding RQ2 (In which type of documents do JAMS citations appear?), as expected, $80.4 \%$ of the citations appear in peer-reviewed journal articles, however, they also appear in conference papers $(9.1 \%)$, book chapters $(4.6 \%)$ and book reviews $(4.4 \%)$.

RQ3 aims to answer which countries (institutions and affiliation of researchers) are citing $J A M S$. The citing articles mostly emanate from the US, the UK, Australia, Taiwan and China; and, from scholars based at the following institutions: Michigan State University, 
Hong Kong Polytechnic University, Pennsylvania State University, Florida State University and City University of Hong Kong. Overall, one in ten citing articles comes from universities in the US, Hong Kong and Australia.

The 60,000+ citations attracted by $J A M S^{\prime} 1,747$ articles and specifically the $18,000+$ documents that cited only the top ten most cited articles in JAMS below (Table 2) share the same profile. That is, the impact of the top ten articles has been observed primarily in the same top five journals, countries and universities described above. For clarity we tabulated this below:

Table 2. Most cited articles published in JAMS

\begin{tabular}{|c|c|c|}
\hline Rank & Article & $\begin{array}{c}\text { Citations (at } \\
\text { time of } \\
\text { analysis) }\end{array}$ \\
\hline 1 & $\begin{array}{l}\text { Bagozzi, R.P., Yi, Y. (1988). On the evaluation of structural } \\
\text { equation models. Journal of the Academy of Marketing Science, 16(1), } \\
\text { 74-94. }\end{array}$ & 8,309 \\
\hline 2 & $\begin{array}{l}\text { Dick, A.S., Basu, K. (1994). Customer loyalty: Toward an } \\
\text { integrated conceptual framework. Journal of the Academy of } \\
\text { Marketing Science, 22(2), 99-113. }\end{array}$ & 2,249 \\
\hline 3 & $\begin{array}{l}\text { Vargo, S.L., Lusch, R.F. (2008). Service-dominant logic: } \\
\text { Continuing the evolution. Journal of the Academy of Marketing } \\
\text { Science, 36(1), 1-10. }\end{array}$ & 2,035 \\
\hline 4 & $\begin{array}{l}\text { Woodruff, R.B. (1997). Customer value: The next source for } \\
\text { competitive advantage. Journal of the Academy of Marketing Science, } \\
\text { 25(2), 139-153. }\end{array}$ & 1,749 \\
\hline 5 & $\begin{array}{l}\text { Berry, L.L. (1995). Relationship marketing of services- } \\
\text { growing interest, emerging perspectives. Journal of the Academy of } \\
\text { Marketing Science: Official Publication of the Academy of Marketing } \\
\text { Science, 23(4), 236-245. }\end{array}$ & 1,286 \\
\hline 6 & $\begin{array}{l}\text { Hair, J.F., Sarstedt, M., Ringle, C.M., Mena, J.A. (2012). An } \\
\text { assessment of the use of partial least squares structural equation } \\
\text { modeling in marketing research. Journal of the Academy of } \\
\text { Marketing Science, } 40(3), 414-433 \text {. }\end{array}$ & 1,092 \\
\hline 7 & $\begin{array}{l}\text { Zeithaml, V.A., Berry, L.L., Parasuraman, A. (1993). The nature } \\
\text { and determinants of customer expectations of service. Journal of } \\
\text { the Academy of Marketing Science, 21(1), 1-12. }\end{array}$ & 1,092 \\
\hline 8 & $\begin{array}{l}\text { Gwinner, K.P., Gremler, D.D., Bitner, M.J. (1998). Relational } \\
\text { benefits in services industries: The customer's perspective. } \\
\text { Journal of the Academy of Marketing Science, 26(2), 101-114. }\end{array}$ & 1,080 \\
\hline 9 & $\begin{array}{l}\text { Payne, A.F., Storbacka, K., Frow, P. (2008). Managing the co- } \\
\text { creation of value. Journal of the Academy of Marketing Science } \\
\text { 36(1), 83-96. }\end{array}$ & 1,064 \\
\hline 10 & $\begin{array}{l}\text { Zeithaml, V.A., Parasuraman, A., Malhotra, A. (2002). Service } \\
\text { quality delivery through web sites: A critical review of extant } \\
\text { knowledge. Journal of the Academy of Marketing Science, 30(4), 362- } \\
375 .\end{array}$ & 1,049 \\
\hline
\end{tabular}

\section{Network Analysis}


As indicated, Scopus' own analytics feature reveals customer satisfaction as the most popular keyword in $J A M S$. We now extend this analysis by using visualization networks using community detection tools. Networks are visual displays representing how elements are connected. It is not possible to present these dynamic images in static text like a journal article so we provide links to dynamic visualizations below.

Communities of citations are detected within networks and they illustrate which elements belong to specific communities by virtue of their strength of association. Several algorithms are already in use to detect these communities (e.g. Chen, Fu and Shang 2009; Liu and Murata 2009) and because we use Kumu, we will present the results based on their SLPA algorithm. This is argued to be more powerful than others in detecting overlapping communities (Xie, Szymanski and Liu 2011).

Authors and author keywords: What topics do $J A M S$ authors predominantly research about? (RQ4) We matched authors and author keywords, using all 654 of the 1,747 articles that have author keywords. Note that usually there are author and index keywords associated with an article. As mentioned earlier, however, there are only author keywords available for $J A M S$. Our analysis agrees with the assessment that customer satisfaction is the most popular keyword used in the history of the journal. In our analysis, we find customer satisfaction is followed (in order of precedence) by marketing strategy, service-dominant logic, metaanalysis, market orientation, advertising, relationship marketing, service quality, innovation and satisfaction (top 10). A dynamic network helps to illustrate this, and is available here: https://bit.ly/2IyahO0 (Link 1).

An extended focus on customer satisfaction highlights that the most relevant connection to be marketing strategy. This is clearly seen in Figure 1 below and is available here as a dynamic file: https://bit.ly/2N4mrBS (Link 2). Comparing the customer satisfaction subnetwork (Link 2) with the overall authors-author keywords network (Link 1), we find that customer satisfaction is more related to marketing strategy, service quality, customer relationship management and customer orientation than to other key terms in the field such as service-dominant logic, metaanalysis, advertising and relationship marketing. This may indicate that $J A M S$ is predominantly a practice-focused journal with an emphasis on managerial implications on applications to customers and service delivery.

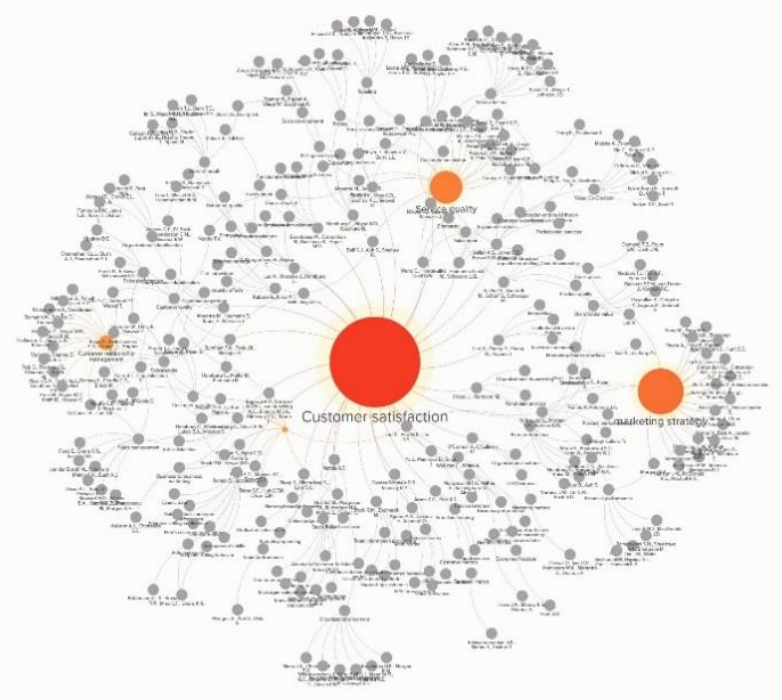


Figure 1. Authors and author keywords network - customer satisfaction subnetwork

Year and author keywords: Figure 2 below shows the keyword frequency in $J A M S$ (RQ4). Note again that keywords were only available from 2003. Note too that 2018 reflects data up to the date of search so it may be incorrect to interpret a slump in that year as the chart suggests. The following diagram (Figure 2) again confirms that customer satisfaction is the most used keyword since 2003 (31 times), most notably in 2011-2012. 2008 saw the most number of documents published that related to service-dominant logic (10), followed by market orientation in 2011 (7). 2011 also marks the number of times all the top five keywords were coined in the same year (19 times). The last time these five terms appeared was in 2008 (15) and 2017 (10). These years constitute significant periods in terms of a focus on these key Marketing concepts.

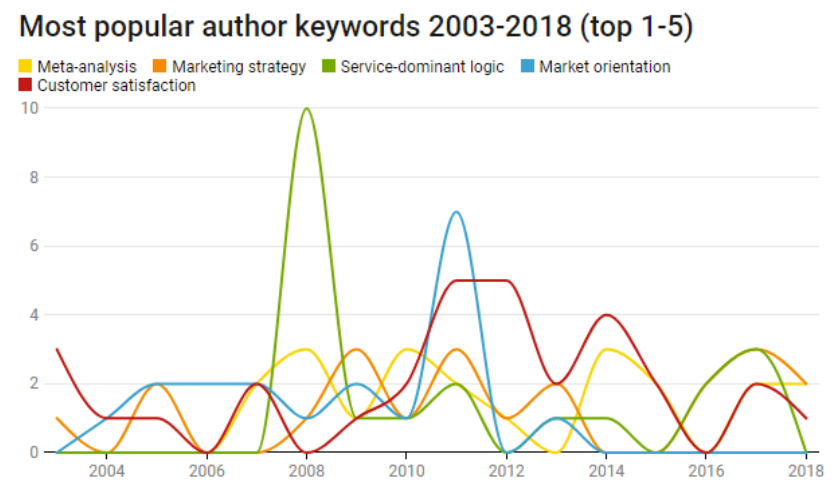

Figure 2. Most popular author keywords 2003-2018 (top 1-5)

Figure 3 provides an analysis of another set of popular keywords. There is no discernible trend in the use of each of these five keywords in JAMS. No reliable conclusions can be drawn from the use of these terms other than that they fluctuate in importance. However, the only years that these five appeared together the most were in 2009 (11) and again in 2017 (10).

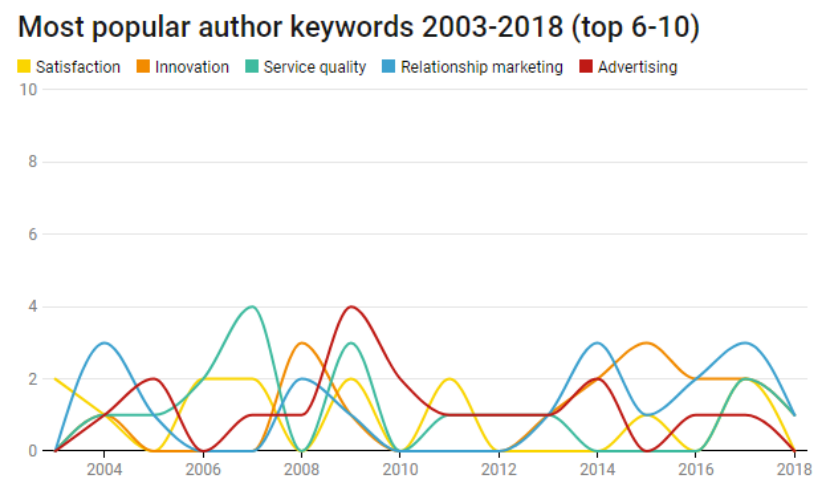

Figure 3. Most popular author keywords 2003-2018 (top 6-10)

Authors and country affiliations: We matched all authors in each article and each of their recorded country affiliations to answer RQ3 (countries of affiliation of researchers who published in JAMS?). That is, where an article is a co-authored piece, we matched each author with their recorded country of affiliation.

It is not surprising that $J A M S$, with a predominantly US-centric focus, would have the US as the major country of author affiliation. The US is followed by Canada, Germany, the 
UK, Australia, Netherlands, China, France, India and Hong Kong in order of significance. We provide a network diagram below (Figure 4) to illustrate this. As this is too large to fit on this page, a dynamic version of this map is available via https://bit.ly/2yTpWrE (Link $3)$.

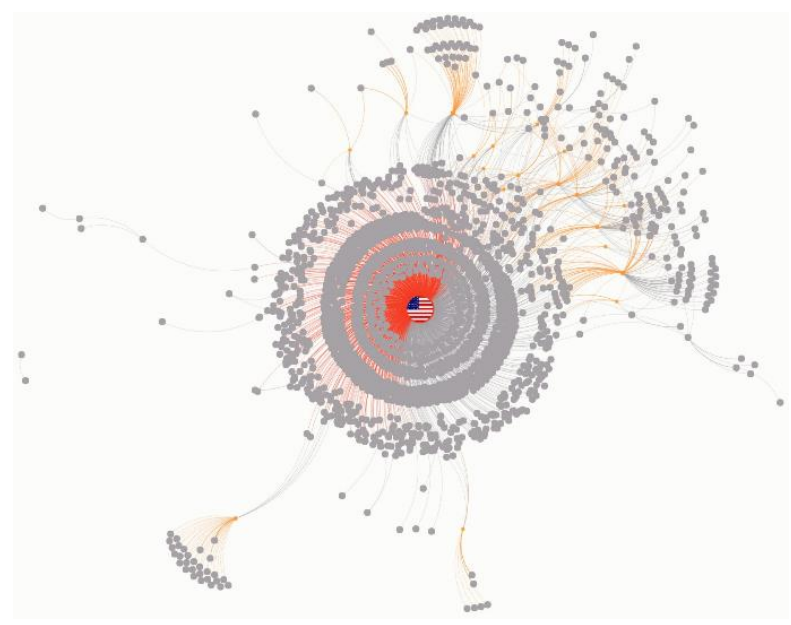

Figure 4. Authors and country affiliations network

Authorship and collaborations: RQ5 aims to answer What is the authorship profile (average authors per article, multiple authorship, etc.) in JAMS? We found 3,933 authors contributing to the 1,747 articles in $J A M S$, this equates to an average of 2.25 authors per article.

Authorship ranges between 1 author and 10 authors for a single article. There were 444 articles written by one author (comprising $25 \%$ of the total), 635 written by two authors (36\%), 498 written by three authors $(29 \%)$ and 170 written by four or more authors $(10 \%)$. Excluding 2018 (an incomplete year of data), Table 3 below shows that co-authored articles ( 2 or more authors) have increased significantly recently. Corresponding with a decline in solo authorship, the last five years has seen the greatest increase in multiple authorship where nine multi-authored articles have appeared in JAMS for every solo-authored article. The trend towards multiple authorship perhaps parallels the increasing interest in Marketing Science as an academic profession, and the exigencies for academics in the field to "publish or perish".

Table 3. JAMS authorship

\begin{tabular}{rrrrrrr}
\hline Period & $\begin{array}{c}1 \\
\text { author }\end{array}$ & $\begin{array}{c}2 \\
\text { authors }\end{array}$ & $\begin{array}{c}3 \\
\text { authors }\end{array}$ & $\begin{array}{c}4 \\
\text { or more }\end{array}$ & $\begin{array}{c}\text { 2 or more } \\
\text { authors }\end{array}$ & $\begin{array}{c}\text { Ratio } \\
\text { solo: multiple }\end{array}$ \\
\hline $2013-2017$ & 25 & 57 & 103 & 64 & 224 & $1: 9.0$ \\
\hline $2008-2012$ & 33 & 84 & 92 & 36 & 212 & $1: 6.4$ \\
\hline $2003-2007$ & 19 & 64 & 78 & 21 & 163 & $1: 8.6$ \\
\hline $1998-2002$ & 28 & 45 & 55 & 12 & 112 & $1: 4.0$ \\
\hline $1993-1997$ & 40 & 55 & 42 & 11 & 108 & $1: 2.7$ \\
\hline $1988-1992$ & 74 & 72 & 40 & 7 & 119 & $1: 1.6$ \\
\hline $1983-1987$ & 67 & 94 & 32 & 2 & 128 & $1: 1.9$ \\
\hline $1978-1982$ & 77 & 77 & 22 & 3 & 102 & $1: 1.3$ \\
\hline $1973-1977$ & 78 & 79 & 22 & 1 & 102 & $1: 1.3$
\end{tabular}


As expected, the US dominates as country of author affiliation, irrespective of the position of the US scholar in a co-authored piece. In a solo article, or appearing as the first author in a co-authored piece, the US appears 1,366 times. By contrast, Canada and Germany appear 62 times, the Netherlands appears only 29 times while the UK and Australia both appear only 23 times. We can conclude that JAMS is undoubtedly a US-centric journal in terms of author affiliation, and by association Marketing Science is a US-centric profession.

RQ6 aims to answer the following question: Who collaborates with whom in JAMS? There is naturally a tendency for scholars from the same country to work together. By looking only at the first and second authors of a co-authored piece, we initially find that US-US scholars (i.e., the US as country of affiliation recorded for the first author and the US as country of affiliation recorded for the second author) have collaborated on 754 articles. This is followed by Canada-Canada with 20 articles and Germany-Germany with 19 articles. What might JAMS authorship data say about international collaborations? In the case of joint authorship consisting of two different countries, the numbers are not high but Canada-US collaborations are preeminent with 18 papers, followed by Germany-US with 16 papers, US-Canada with 12, and the US-UK with 10 papers. Although cross-national and cross-cultural research is present in JAMS and attention is paid to international markets (as suggested by the text mining analysis presented later), this fact seems not to be clearly represented by co-authorships.

With regard to collaborations between any two countries among the top 10 affiliations, the US collaborates more (48 papers), followed by Germany (24), Canada (21), Australia (12) and the UK (11). The UK is associated with 57 publications in total; but between any two authors/articles where the UK is listed as first author, it collaborations can be seen with authors from the US, Canada, Australia, Netherlands, and so on. A dynamic network diagram for the UK publications can be seen in the following link: https://bit.ly/2KoX3sd (Link 4).

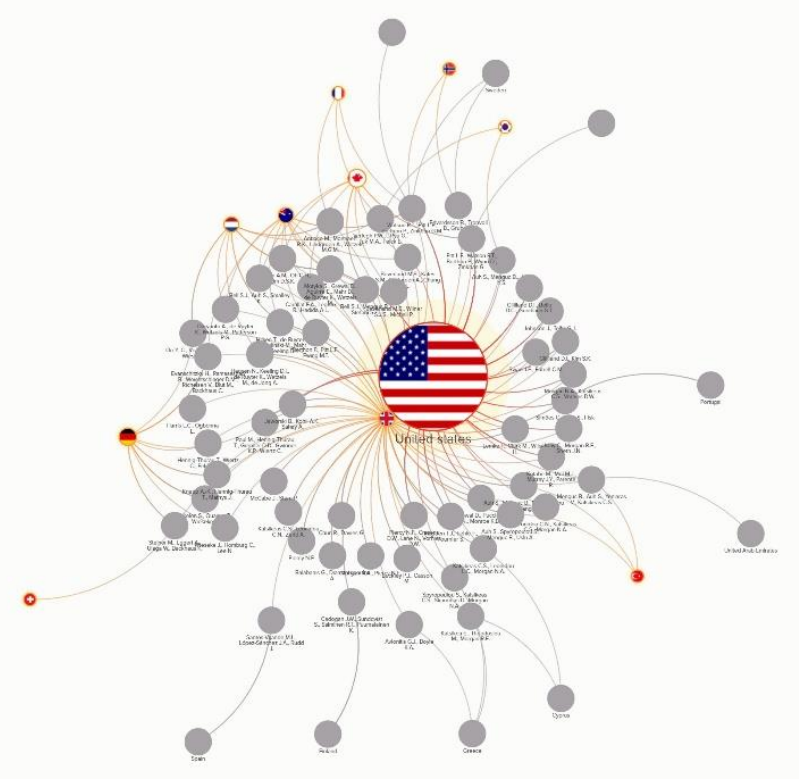

Figure 5. Authors and affiliations - UK sub-network (indirect/2-degree focus).

The diagram provided above applies an 'indirect' focus on the element 'United Kingdom'. In Kumu, focus can be direct (one-degree), indirect (two-degree) or extended (three-degree). In 
the author-country network example provided, a direct focus shows all authors residing in the United Kingdom, an indirect focus shows all authors residing in the UK and other countries if a multi-authored article, while an extended focus shows all the residential connections of all 1,747 articles to all affiliated countries.

What do authors collaborate on? By matching author keywords with all multi-authored articles (two or more authors), we still find customer satisfaction as the most significant topic of interest among collaborators. This is followed by meta-analysis, market orientation, relationship marketing, service-dominant logic, service quality, innovation, performance, satisfaction and advertising. Note that the results are similar to the top keywords discussed earlier except for a new entrant on this list (performance) which replaced customer relationship management. What is also interesting are the topics beyond the top ten listed. Results reveal that there is also strong research collaboration interest in the following areas of Marketing scholarship: new product development, corporate social responsibility, customer orientation, firm performance and loyalty.

\section{Communities}

We mapped the author keywords available from 2003 to 2018 to answer RQ7 (Which are the main research communities in JAMS?). Using Kumu's SLPA algorithm. By doing so, a number of communities were found. A community is formed where a group of elements (in this case, author keywords) tend to group together by their strength of association (" 1 " being highest). Each community also shows those keywords that loosely belong to one community but which are clearly marked in Kumu as having stronger ties with another more distant community. They usually have a lower strength of association. We discarded these secondary associations and focused our analysis on those terms that shared strongly associated community values. We find three such communities: 1 . Firm capability and performance; 2. Brand and value co-creation; and 3. Customer service

Community 1: Firm capability and performance: Figure 6 below shows 18 items that exhibit membership to this community. Strong ties, as represented by their strengths of association, are closer to the edge as indicated by a number near 1.0. We chose an arbitrary cutoff of $70 \%$ association strength. Only government networking, channel networking and customer trust exhibit low association values $(<.70)$. We refer to these communities as relating to the area of 'Firm capability and performance' due to the nature of the member elements. This is the largest community detected in Kumи. This community displays the strongest interest in these topics throughout the journal's history based on all of the keywords used in the 654 articles under consideration in this community cluster.

This network demonstrates the importance of topics in Marketing that deal with strategy relating to branding, partnerships, customer solutions, B2B, and firm performance. An example is Lam, Shankar, Erramilli and Murthy's (2004) highly cited article 'Customer value, satisfaction, loyalty, and switching costs: An illustration from a business-to-business service context' (736 citations) which shows the interrelationships between customer value, satisfaction, loyalty, and switching costs in a business-to-business (B2B) service context, a departure from the usual investigation of these topics in business-to-consumer (B2C) settings.

To take another example, Madden, Fehle and Fournier's (2006) 'Brands matter: An empirical demonstration of the creation of shareholder value through branding' (189 citations), provides empirical evidence to the branding-shareholder value creation link 
demonstrating how marketing affects firm performance. By using community detection tools it can be shown how key terms cluster in a specific area of Marketing scholarship. This is illuminating in terms of showing the 'geography' of Marketing Science as an academic discipline.

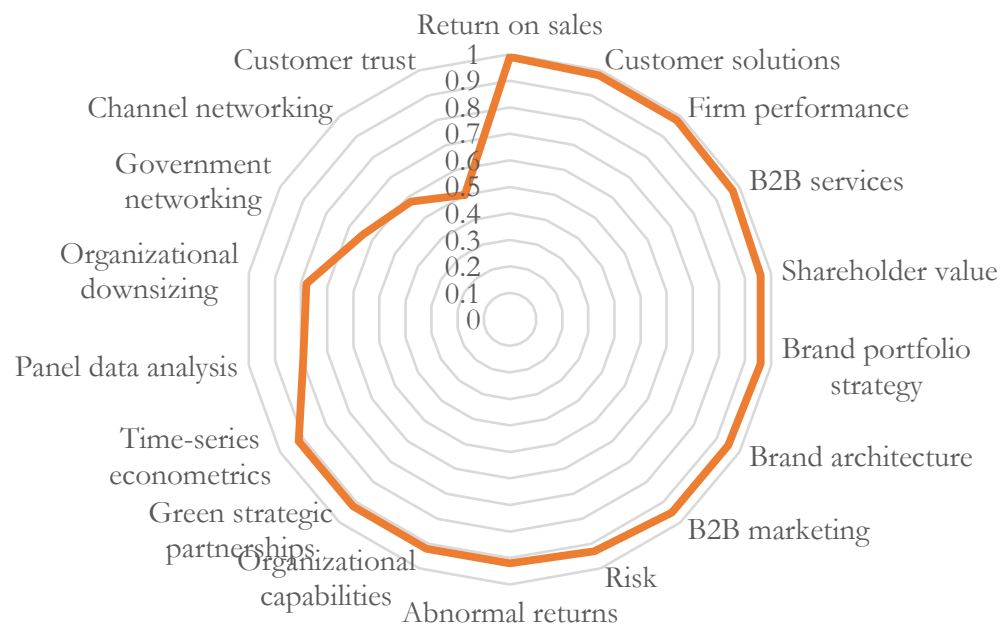

Figure 6. Network community 1: Firm capability, performance and value

Community 2: Brand and value co-creation: The next network we draw attention to is the area of "Brand and value co-creation". Terms used in this community stem from topics relating to specific brand-related strategies rather than those concerned with brand architecture which belonged to Community 1.

We noted earlier that service-dominant logic is not distant from customer satisfaction as a term in common use in JAMS. We also showed the respective rank of Vargo and Lusch's 2008 article 'Service-dominant logic: Continuing the evolution' in relation to the most highly cited papers in the journal. This further illustrates the importance of this topic and its place in a JAMS community as defined by detection algorithms. However, this network is more connected to the concept of branding than other elements shown in Figure 7.

Another example of an article strongly connected to this community is Yoo, Donthu and Lee's (2000) 'An examination of selected marketing mix elements and brand equity' (896 citations). This paper investigates the relationship between marketing mix and brand creation (e.g., loyalty, quality, associations and awareness). In this paper the authors reported elements that promote either low or high brand equity. The positive perception of the scholarly community towards their study and its results must be significant, as shown by its citation count. Of similar influence in the area of service marketing is Berry's 2000 article 'Cultivating service brand equity' (625 citations) which argues for the value of service branding as a fundamental determinant in service marketing. 


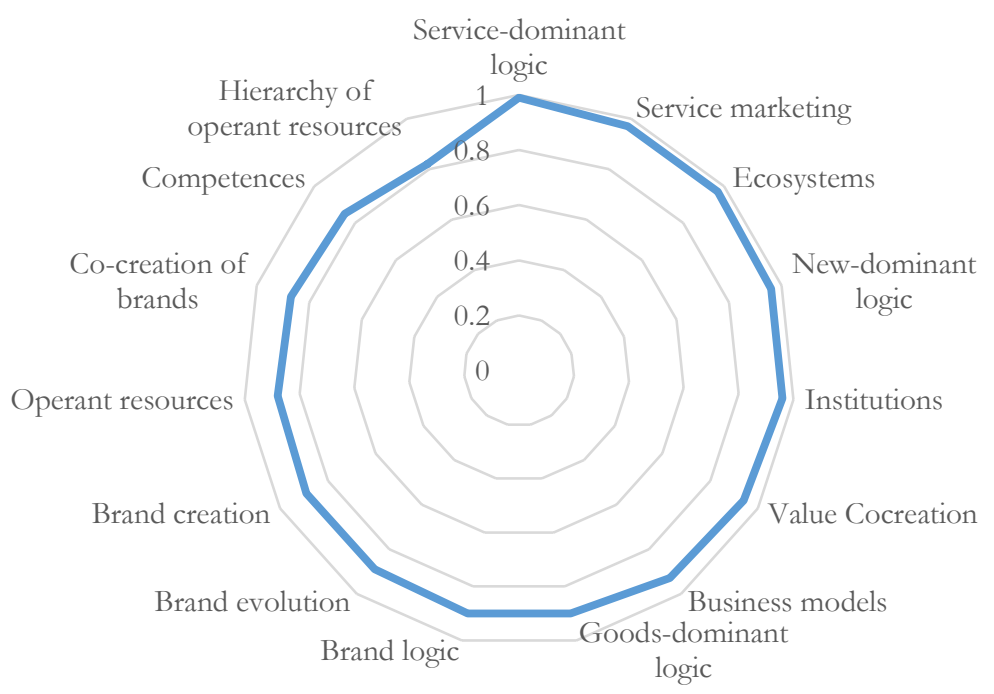

Figure 7. Network community 2: Brand and value co-creation

Community 3: Customer service: The concept of customer satisfaction has been the subject of much investigation amongst scholars in JAMS. It is no surprise to find this in one of the communities we outline. However, where previously we merely identified it as a muchdiscussed topic, its relationship with other terms used in $J A M S$ is now shown clearly (see in Figure 8 below).

Szymanski and Henard's (2001) paper 'Customer satisfaction: A meta-analysis of the empirical evidence' (931 citations) illustrates the relationships. This highly regarded paper summarizes findings from several articles on customer satisfaction showing the complex considerations behind the issue of why customers are more or less satisfied. They sum up their findings by concluding that equity and disconfirmation are most strongly related to customer satisfaction.

Related to this paper are studies on customers' emotions, such as that provided in Bagozzi, Gopinath and Nyer's (1999) 'The role of emotions in marketing' (999 citations). They find that emotions are markers, mediators and moderators of consumer responses. This can be seen belonging to the term customer satisfaction in Figure 8 because of the association of emotions to customers' volitions, goal-directed behavior and decisions.

The other related terms shown in the Figure 8 community network is the interrelationships that can be seen between terms such as customer and employee relations and customer and firm value, and even CEO compensation. The article by Luo, Wieseke and Homburg (2012) illustrates the interconnectedness of these marketing concepts. They report that customerand employee-firm relations can be used in leveraging executive incentive structures to create customer and firm value both directly and indirectly via the mediator of customer satisfaction. They also report that increases in the proportion of CEOs' long-term equitybased compensation positively influence actions that build customer- and employee-firm relations. The community diagram below confirms the connections made among these key terms. 


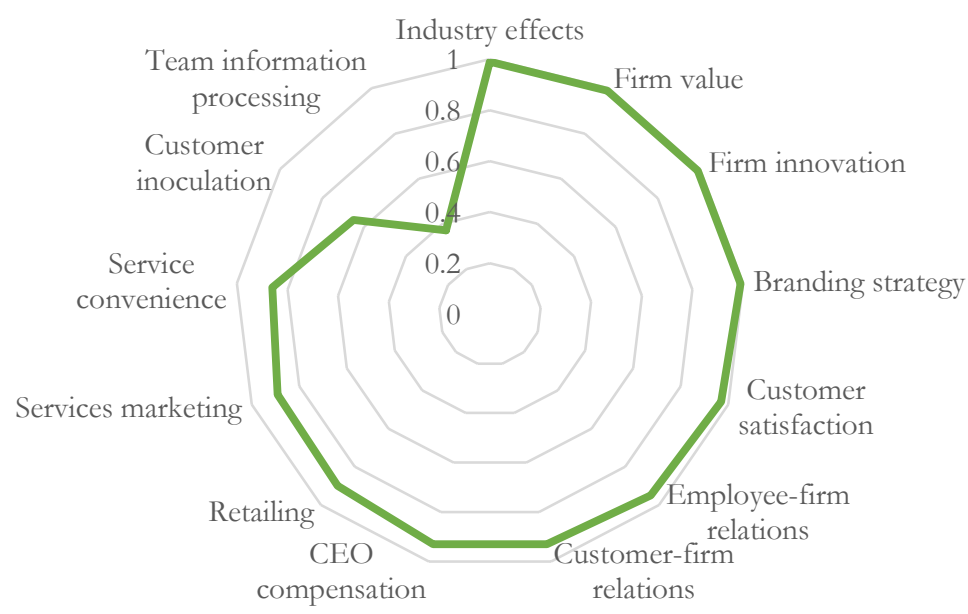

Figure 8. Network community 3: Customer service

\section{Text Mining Analysis}

We performed text mining using WordStat (version 7.1.21) on all available abstracts as a method of data triangulation. The following results summarize the main identified themes in JAMS (RQ8). Consistency with the previous findings given in earlier sections can be clearly seen, thereby confirming our analytical results.

A total of 1,619 cases (abstracts), containing 201,098 words, were processed for text mining analysis. Our first goal was to identify the main themes addressed by the papers as represented in their abstracts. We used the topic extraction function of WordStat to cluster the topics into nine main themes: brands' strategic value, firms' strategy and financial performance, customer service, sales, marketing communications, retailing, distribution channel, global markets, and corporate social responsibility (CSR). By analyzing co-occurrences of keywords present in those themes we also identified several distinct research areas within each theme. These themes are further analyzed in the subsequent sub-sections.

Table 4 shows the 9 themes and the main areas of research within each theme and the relative proportion of each in the journal. We address each theme in detail below.

Table 4. Themes and areas of research

\begin{tabular}{|c|c|c|c|c|c|c|}
\hline Theme & Areas of research & Eigenvalue & $\begin{array}{c}\% \\
\text { var }\end{array}$ & Freq & Cases & $\%$ cases \\
\hline $\begin{array}{c}\text { Brands' strategic } \\
\text { value }\end{array}$ & $\begin{array}{l}\text { brand equity, brand } \\
\text { extensions, role of } \\
\text { advertising on firm } \\
\text { intangible values }\end{array}$ & 2.21 & 1.4 & 765 & 542 & $33.48 \%$ \\
\hline $\begin{array}{c}\text { Firms' strategy and } \\
\text { financial } \\
\text { performance }\end{array}$ & $\begin{array}{l}\text { innovation and } \\
\text { firms' financial } \\
\text { performance, impact } \\
\text { of strategic alliances } \\
\text { on firms' financial } \\
\text { performance, brand } \\
\text { performance and } \\
\text { firms' financial } \\
\text { performance, }\end{array}$ & 2.17 & 1.29 & 655 & 449 & $27.73 \%$ \\
\hline
\end{tabular}




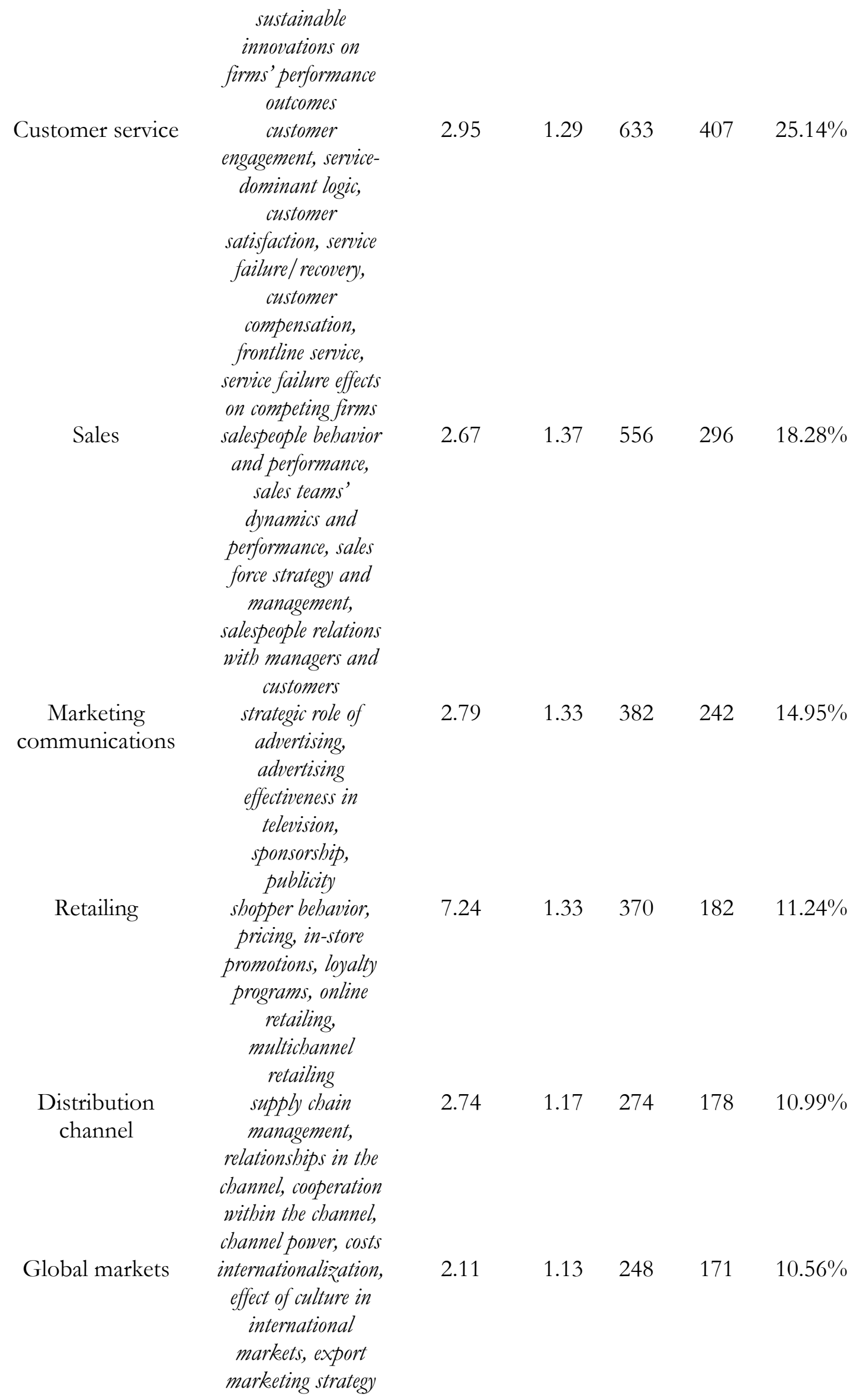




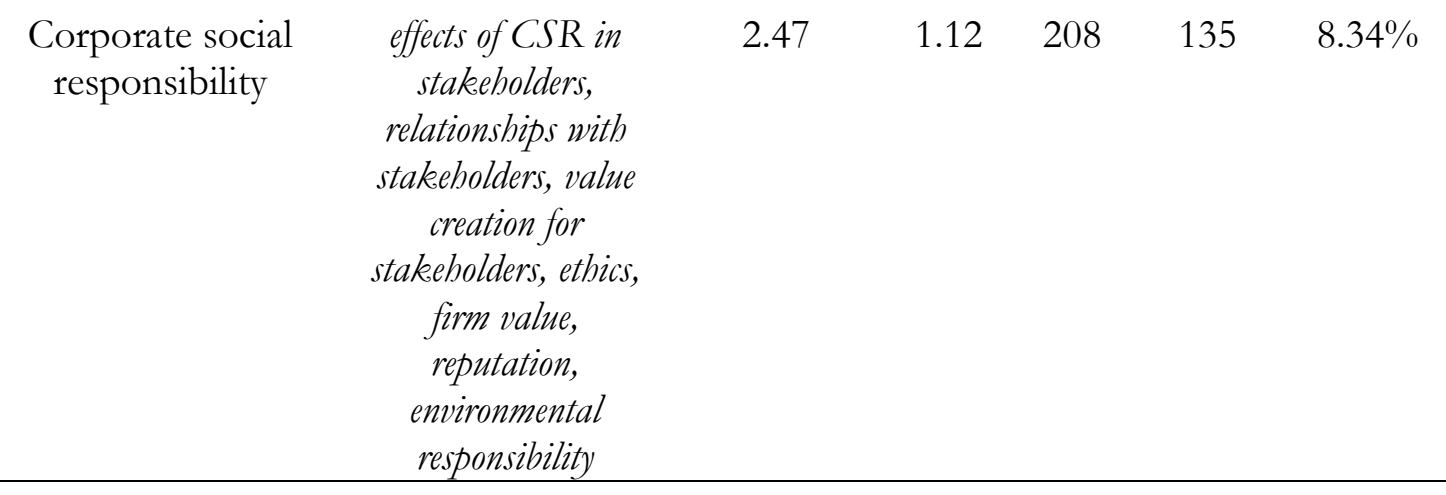

Brands' strategic value: This theme addresses research related to brand value from a strategic approach; that is, how brands and branding contribute to firms' value, positioning, and strategy within the market.

Thirty-eight main keywords are present in this theme including brand extension, purchase, parent brand, equity, category, product, segmentation, hedonic, personality, and positioning. One relevant area of research within this topic is brand equity. For example, Beverland et al (2015) contribute to the brand, marketing, and strategic management literature by pointing out how design thinking can be applied to maintaining market relevance through innovation without damaging brand equity.

Another important area of research within this theme relates to brand extensions (e.g. Parker et al 2018). This includes issue related to how mental associations are created in consumers' minds, and how they affect brand extension evaluations based on the parent brandextension fit (Miniard et al 2018). We found that the role of advertising on firm intangible values is also addressed in this theme. For example, Wang et al (2009) investigate firms' varying effectiveness in creating brand equity through advertising. Figure 9 shows a longitudinal analysis of this theme spanning the period under consideration (1973-2018). The results suggest that there has been increasing interest in this theme during two specific periods: 2012-2014 and 2016-2017. Why this might be is a matter of conjecture. 


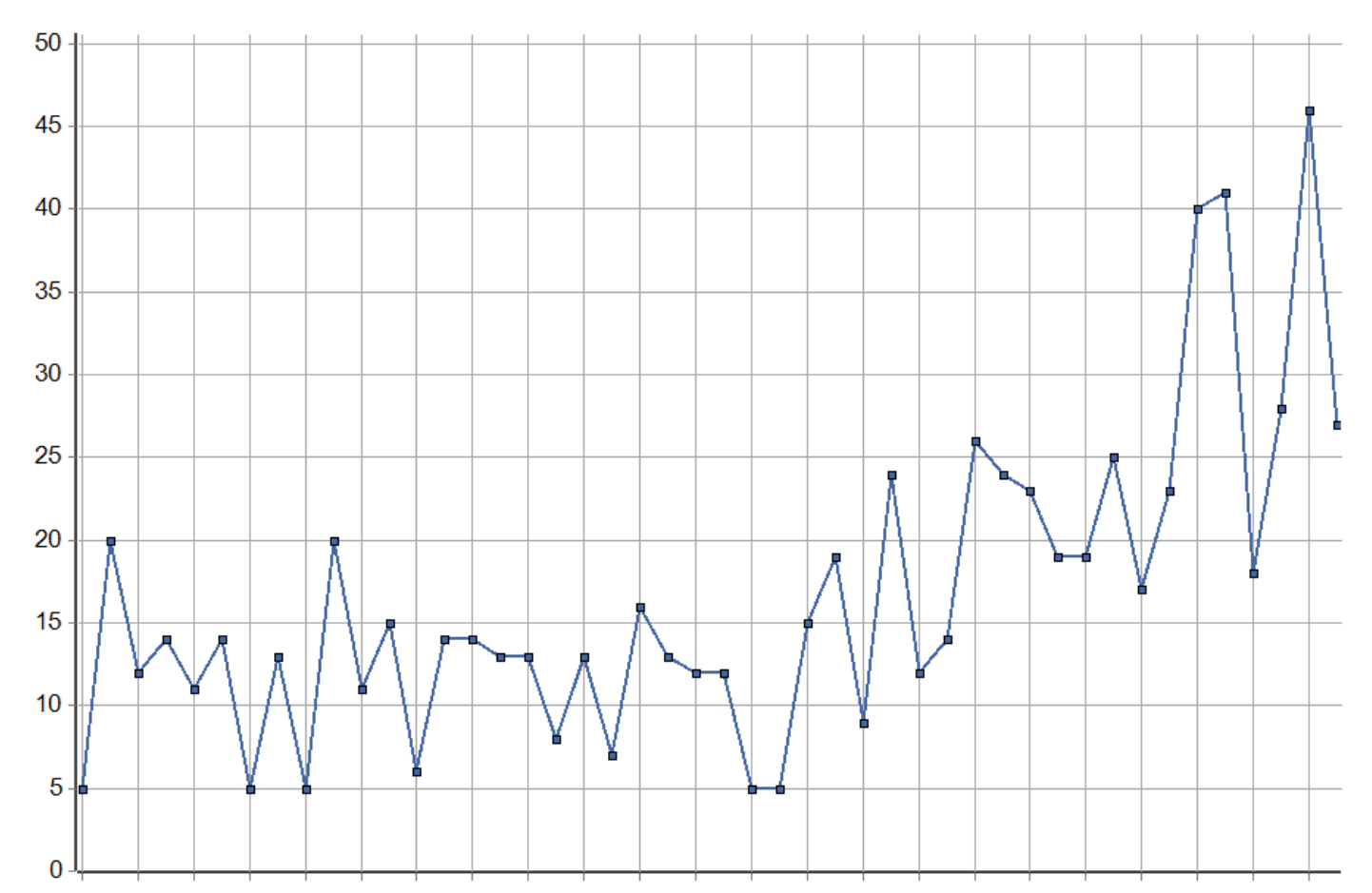

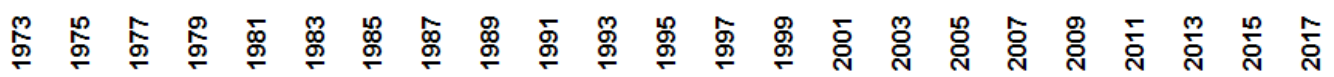

Figure 9. Evolution of the brands'strategic value theme (1973-2018)

Firms' strategy and financial performance: This theme addresses firms' strategy and strategic alliances, new product development, innovation, sustainability, and its impact on firms' financial performance. 40 main keywords were found including performance, financial, strategic alliance, competitive, sustainability, assets, shareholder, NPD (new product development), innovation, and profitability.

Further assessment of the keywords included in this theme suggests one relevant area of research related to innovation and firms' financial performance. For example, Arunachalam et al (2018) draw from the marketing capabilities and innovation literatures to identify the process by which a firm's entrepreneurial orientation impacts profits. The authors point out that entrepreneurial orientation is dependent on marketing capabilities. Of note too is research of the impact of strategic alliances on firms' financial performance, such as Wu et al's (2015) study on stock market reactions to NPD horizontal collaboration.

Another area of research within this theme is related to brand performance and firms' financial performance. For example, Hsu et al (2016) investigate how financial markets value brand architecture strategies pursued by firms. The role of sustainable innovations on firms' performance outcomes is also present as a critical topic within this theme. For example, Varadarajan (2017) investigates firms' sustainable innovations capabilities as a source of competitive advantage. He does this by addressing the performance outcomes of a sustainable innovations orientation. The multidimensional scaling chart below (Figure 10) shows the strongest ties among keywords within this theme as represented by the strength of association based on Jaccard's index of similarity. 


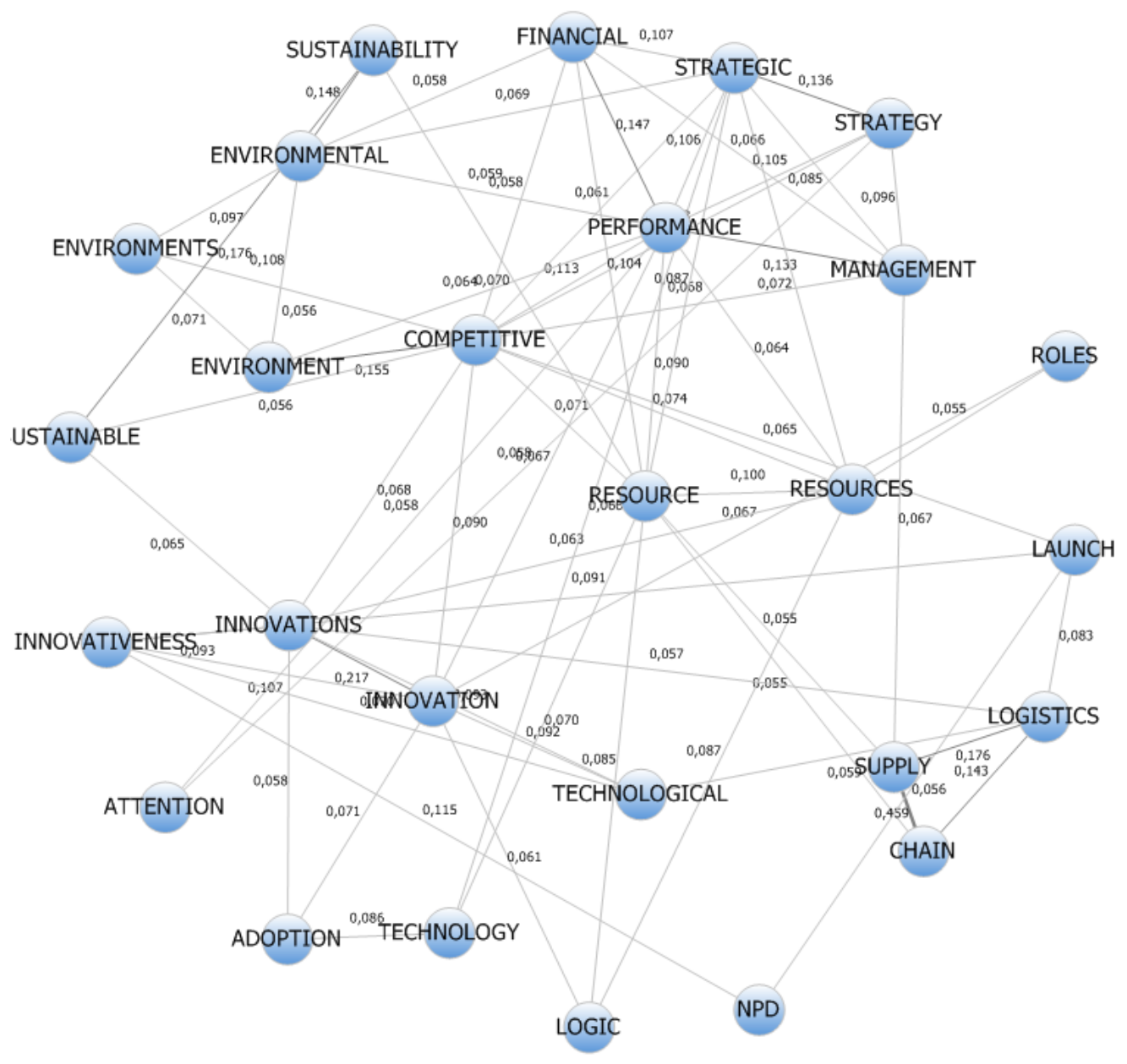

Figure 10. Strength of associations among topics in the theme firms' strategy and financial performance

Customer service: Research within this theme addresses strategic aspects of customer service such as customer engagement and customer satisfaction. A prominent approach here is from the service-dominant logic literature. Among the main 16 keywords related to this theme we find service-dominant logic, engagement, experience, satisfaction, emotions, failure, recovery, frontline, employees, and compensation.

One main area of research within this theme is focused on customer engagement. For example, Harmeling et al (2017) present a typology of customer engagement and strategic elements contributing customer outcomes and firm performance. The service-dominant logic approach to customer engagement research is represented by Hollebeek et al (2016). They develop an integrative, service-dominant logic-informed framework of customer engagement which allow the authors to identify three customer engagement benefits and their application to customer relationship management.

The customer engagement and customer satisfaction links are also explored as a prominent research area within this theme. A key paper in this area is Kumar et al (2017). They develop a service-dominant logic-based framework to facilitate customer engagement in service. The authors also analyze the influence of service experience on customer satisfaction and emotional attachment and its effects on customer engagement. 
Another pivotal area of research within this theme is service failure/ recovery which has been addressed both at a firm-level and at a customer-level. For example, Rasoulian et al (2017) develop a framework to analyze the impact of service crisis recoveries on a firm's performance. By contrast, Hogreve et al (2017) analyze recovery time and customer compensation expectations for service failures that cannot be immediately redressed. The effects of frontline service employees' behavior during service failure (e.g. Lim et al 2017), and service failure effects on competing firms (e.g. Allen et al 2015) are topics also addressed within this theme.

Sales: This theme addresses strategic variables affecting salespeople's behavior and performance. This includes sales force strategies and salespeople interactions with both customers and managers. The sales theme is related to 20 main keywords used in the abstracts including salespeople, selling, stress, manager, conflicts, motivation, behaviors, leadership, skills, and interpersonal.

A major area of research within this theme is focused on salespeople behavior and performance. As an example of this area of research, van der Borgh and Schepers (2017) analyze the effect of conservative selling behavior in new product selling performance in a B2B context. Sales teams' dynamics and performance (Auh et al 2014) and sales force strategy and management (Cron et al 2014) are also prominently researched within this theme.

We identified additional research related to salespeople relations with managers and customers under this theme. For example, Shannahan et al (2013) investigate factors influencing sales performance to find that sales performance is highest when salespeople are highly coachable, highly competitive, and under transformational leadership. Homburg et al (2014) analyze salespeople's misperceptions of customer commitment. They conclude that salespeople's upwardly biased perception of customer commitment engage in less relationship-building effort, which in turn negatively affects customer behavior.

Marketing communications: This identified theme covers a wide range of areas including how advertising impact firms' performance, the effectiveness of advertising and sponsorship, and ethics in marketing communications. The main 25 keywords found within this theme include advertising, television, audience, recall, message, sponsorship, credibility, effectiveness, exposure, and media.

One major area of research within this theme is the strategic role of advertising for firms. For example, Sridhar et al (2014) point out that advertising spending and inventory holding increase sales, while $\mathrm{R} \& \mathrm{D}$ spending does not, and advertising and $\mathrm{R} \& \mathrm{D}$ spending increase firm value, while inventory holding does not.

The use of advertising in international markets is also noted as a key topic addressed within this area of research (e.g. Song et al 2018). Another area of research is advertising effectiveness in television (e.g. Brasel and Gips 2014). This area includes the effect of feelings evoked by television advertisements on attitudes towards the advertisement (Boles and Burton 1992) and ethical issues that advertising professionals face when using television advertising targeted to children (LaFleur et al 1995). Researchers have also addressed marketing communications tools such as sponsorship, including investors' perceptions of sponsorship's ability to increase brand equity (Mazodier and Rezaee 2013) and the effectiveness of sponsorship in comparison to television (and as a complementary tool to television 
advertising) (e.g. Olson and 2009). The effectiveness of publicity, compared to advertising, is also noted as featuring under this theme (Eisend and Küster 2011).

Retailing: This theme addresses key factors affecting the retailing sector such as prices, segments, promotions, and the internet. The 20 main keywords identified within this theme include store, retail, shopping, retailers, shoppers, patronage, internet, segments, price, and promotions.

One major area of research within this theme is shopper behavior. For example, Albrecht et al (2017) investigate how shopping stress negatively affects consumers' purchase likelihood. In their paper they suggest approaches to structuring the shopping environment to appeal consumers. Pricing is also identified as an important theme (e.g., Zielke and Komor 2015). These authors analyze differences in price-role orientations between economically developed and emerging markets and how these differences influence store brand and store format preferences. Other related research areas are In-store promotions (Leeflang and Parreño-Selva 2012) and loyalty programs (Meyer-Waarden and Benavent 2009). These too can clearly be seen as emerging in this research theme. Finally, the impact of the internet in modern retailing is also addressed in two related research areas: online retailing (KukarKinney and Close 2010) and multichannel retailing (Mahar et al 2014).

Distribution channels: This theme focused on several topics in the distribution channel including relationships in the channel, supply chain management, and costs. Within this theme 24 main keywords were identified including: supplier, channel, manufacturer, buyer, seller, logistics, power, cooperation, costs, and industrial.

One major research area occurring within this theme is supply chain management. An example of this area of research is Esper et al (2010) who-drawing upon literature in marketing, logistics, supply chain management and strategy-introduce a conceptual framework of demand and supply integration (DSI). A different service-dominant logic approach to supply chain management is proposed by Lusch et al (2010).

Another important area of research that occurs within this theme is relationships in the channel including cooperation within the channel (Scheer et al 2015) and power in the channel (Johnston et al 2017). Research on costs within the channel is also clearly seen as major research area under this theme (e.g. Sheng et al 2018).

Global markets: This theme consists of research related to internationalization, international markets, export, the impact of culture in businesses, and the political/legal environment of businesses. The 26 main identified keywords include: international, culture, alliances, global, foreign, political, values, export, government, and legislation.

One main area of research that features within this theme is internationalization (e.g. Cavusgil and Cavusgil 2012) including the internationalization of small-medium enterprises (Kamakura et al 2012) and early internationalization of born-global firms (Weerawardena et al 2015).

The effect of culture in international markets is also addressed under this theme. For example, Nakata and Sivakumar (2001) analyze the effects of national culture on transnational organizations management. A cross-cultural framework has also been adopted in this area of research. For example, Swoboda et al (2016) analyze the role of culture in the corporate reputation of a multinational corporation in 40 countries, while Blodgett et al (2001) identify differences in work-related values of employees across different nationalities. 
Another area of research is devoted to export marketing strategy. For example, Katsikeas and Vorhies (2012) analyze the drivers of export market performance to explaining firms' international competitiveness.

Corporate social responsibility: Research occurring under this theme address topics related to firms' corporate social responsibility, reputation, and business ethics. This theme includes 13 main keywords including: corporate social responsibility, CSR, stakeholder, reputation, green, climate, motives, ethics, moral, and justice. One main area of research within this theme is the effects of CSR in stakeholders including relationships with stakeholders. For example, Sen et al (2006) analyze stakeholders' reactions to CSR actions and how stakeholder attributions regarding the genuineness of the company's motives moderate stakeholders' reactions. Peloza and Shang (2011) review literature on CSR to synthesize which CSR activities create value for stakeholders. Another identified area of research is related to ethics (Smith, 2009) as both CSR and ethics frame organizations response to normative societal expectations (Martin et al 2011). Other CSR contributions to companies such as firm value (Lenz et al 2017), reputation (Nikolaeva and Bicho 2011), and environmental responsibility (Xie et al 2015) also feature prominently within this theme.

\section{Key Constructs}

In addition to topic extraction, word frequency analysis was used to identify 851 key marketing constructs (RQ9) using longitudinally-derived data from JAMS. Table 5 shows the top 20 identified marketing constructs used throughout the journal's history.

Table 5. Top 20 identified marketing constructs

\begin{tabular}{|c|c|c|c|c|c|}
\hline Construct & Freq. & $\begin{array}{c}\text { No. } \\
\text { Cases }\end{array}$ & $\begin{array}{c}\% \\
\text { cases } \\
\end{array}$ & Length & $\begin{array}{l}\text { TF・ } \\
\text { IDF* }\end{array}$ \\
\hline Customer satisfaction & 114 & 55 & $3.40 \%$ & 2 & 167.5 \\
\hline Consumer behavior & 83 & 55 & $3.40 \%$ & 2 & 121.9 \\
\hline Financial performance & 44 & 31 & $1.91 \%$ & 2 & 75.6 \\
\hline Service quality & 62 & 26 & $1.61 \%$ & 2 & 111.2 \\
\hline Job satisfaction & 40 & 26 & $1.61 \%$ & 2 & 71.8 \\
\hline Purchase intentions & 28 & 22 & $1.36 \%$ & 2 & 52.3 \\
\hline Product category & 25 & 21 & $1.30 \%$ & 2 & 47.2 \\
\hline Public policy & 24 & 20 & $1.24 \%$ & 2 & 45.8 \\
\hline Sales force & 35 & 19 & $1.17 \%$ & 2 & 67.6 \\
\hline Service failure & 36 & 18 & $1.11 \%$ & 2 & 70.3 \\
\hline Supply chain & 37 & 17 & $1.05 \%$ & 2 & 73.2 \\
\hline Customer loyalty & 26 & 17 & $1.05 \%$ & 2 & 51.4 \\
\hline Service providers & 23 & 17 & $1.05 \%$ & 2 & 45.5 \\
\hline Consumer satisfaction & 21 & 17 & $1.05 \%$ & 2 & 41.6 \\
\hline Product performance & 28 & 16 & $0.99 \%$ & 2 & 56.1 \\
\hline Sales management & 25 & 15 & $0.93 \%$ & 2 & 50.8 \\
\hline Corporate social responsibility & 15 & 14 & $0.86 \%$ & 3 & 30.9 \\
\hline Service recovery & 30 & 14 & $0.86 \%$ & 2 & 61.9 \\
\hline Service provider & 23 & 14 & $0.86 \%$ & 2 & 47.5 \\
\hline Brand equity & 21 & 14 & $0.86 \%$ & 2 & 43.3 \\
\hline
\end{tabular}

* Term frequency weighted by inverse document frequency. 
The identified marketing constructs provide a way to consolidate identification of the themes described above. The constructs, in fact, largely mirror the themes. Thus, customer satisfaction ( $\mathrm{n}=55)$ is highly related to the customer service theme. Consumer bebavior $(\mathrm{n}=55)$ is related to the sales theme. And financial performance $(\mathrm{n}=31)$ - the third construct in importance based on case appearance-is related to the firms' strategy and financial performance theme. A deeper look into the constructs related to one of the identified themes (brands' strategic value) shows a total of 38 brand-related constructs, brand equity being the most frequent construct ( $\mathrm{n}=14)$, followed by brand attitudes $(\mathrm{n}=8)$, brand personality $(\mathrm{n}=8)$, parent brand $(\mathrm{n}=8)$, brand loyalty $(\mathrm{n}=7)$, and brand names $(\mathrm{n}=7)$. Figure 11 depicts all 38 identified brand-related constructs. In effect, the figure below shows, at a glance, the relative thematic concerns, related to brand issues, of the journal throughout its history.

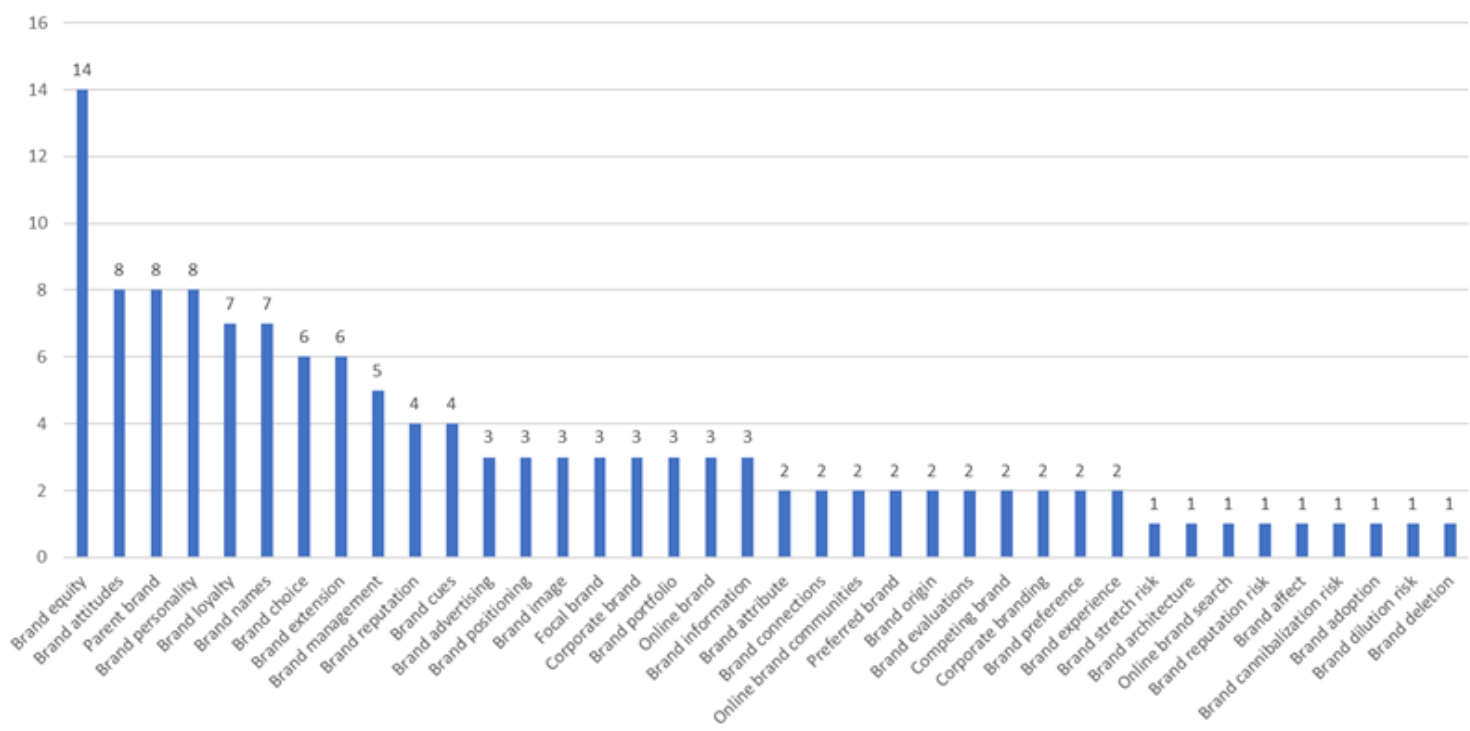

Figure 11. Identified brand-related constructs

Substantive conclusions can be drawn by comparing thematic analyses with the data identified from the most cited articles. For example, Dick and Basu's (1994) article (the second most cited article) addresses customer loyalty while Vargo and Lusch's (2008) article (the third most cited article) addresses service-dominant logic. The most cited article, Bagozzi and Yi (1988), and the sixth most cited article, Hair, Sarstedt, Ringle and Mena (2012), highlight JAMS's contribution to methodology and data analysis techniques in marketing research respectively. Conveniently, the identification of the most cited articles parallels the concerns addressed under these themes.

\section{Abstract Content Analysis}

Finally, abstracts were content-analyzed to identify methodological approaches and data analysis techniques (RQ10) used in the papers. Of the sample, 1,544 abstracts were able to be coded using the following categorization schema: Literature review, Conceptual/ Theoretical, Empirical (quantitative), Empirical (qualitative), and Empirical (Mixed-methods). Following standard procedure in content analysis, an intercoder reliability analysis was performed on $10 \%$ of the sample. The results of Cohen's kappa (Cohen, 1960) suggest a substantial agreement (.67) (Landis and Koch 1977). The results of the content analysis show that the empirical quantitative approach is the most common research methodology used in the journal, accounting for $74.35 \%$ of all analyzed abstracts. This is followed by 
conceptual/theoretical papers (20.14\%). Qualitative research methodology accounted for $2.33 \%$ of abstracts, literature review papers for $2.01 \%$, and mixed-methods research for $1.17 \%$. Table 6 shows the longitudinal analysis of methods used. Figure 12 depicts a graphical representation of the data.

Table 6. Longitudinal analysis of methods used (1973-2018)

\begin{tabular}{lcccccccccc}
\hline \multicolumn{1}{c}{ Method } & 1973 & 1978 & 1983 & 1988 & 1993 & 1998 & 2003 & 2008 & 2013 & 2018 \\
& - & - & - & - & - & - & - & - & - & \\
& 1977 & 1982 & 1987 & 1992 & 1997 & 2002 & 2007 & 2012 & 2017 & \\
\hline $\begin{array}{l}\text { Empirical } \\
\text { Quantitative) }\end{array}$ & 76 & 107 & 137 & 117 & 98 & 89 & 139 & 168 & 194 & 23 \\
$\begin{array}{l}\text { Conceptual/ } \\
\text { Theoretical }\end{array}$ & 45 & 33 & 41 & 36 & 28 & 42 & 20 & 45 & 18 & 3 \\
\hline $\begin{array}{l}\text { Empirical } \\
\text { Qualitative }\end{array}$ & 3 & 3 & 1 & 1 & 0 & 4 & 5 & 10 & 8 & 1 \\
\hline $\begin{array}{l}\text { Literature } \\
\text { Review }\end{array}$ & 7 & 3 & 3 & 6 & 2 & 3 & 0 & 2 & 3 & 2 \\
\hline $\begin{array}{l}\text { Empirical } \\
\text { (Mixed } \\
\text { Methods }\end{array}$ & 1 & 0 & 0 & 0 & 1 & 1 & 4 & 7 & 3 & 1 \\
\hline & 132 & 146 & 182 & 160 & 129 & 139 & 168 & 232 & 226 & 30 \\
\hline
\end{tabular}

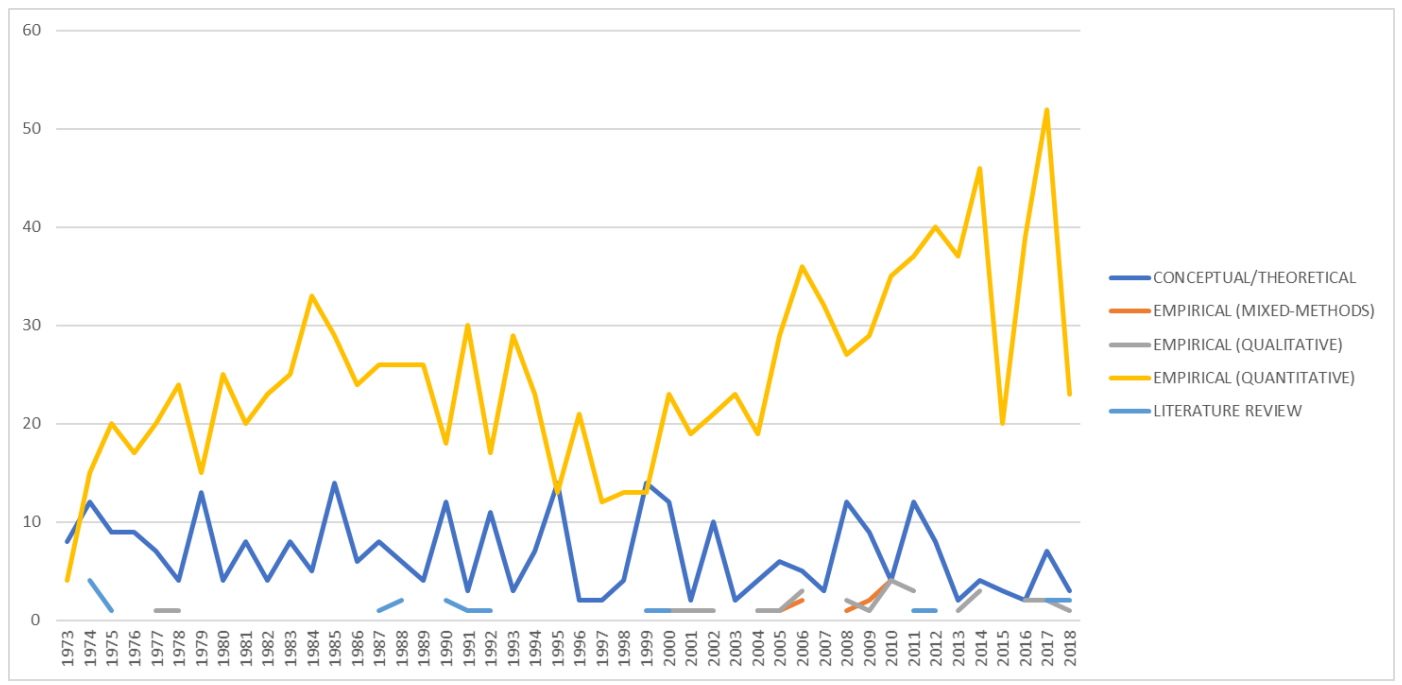

Figure 12. Distribution pattern of methods used (1973-2018)

Only 165 abstracts provided enough information to clearly identify the data analysis technique used in the paper. Regarding quantitative analysis techniques, structural equation modelling (SEM) and meta-analysis rank first (20 cases each), followed by Bayesian analysis $(\mathrm{n}=7)$, content analysis, conjoint analysis, regressions, and cluster analysis (6 cases each), partial least squares (PLS) and correlations (5 cases each). Path analysis, MultitraitMultimethod Matrix and log-linear Models account for 4 cases each. Other quantitative analysis techniques include ANOVA, MANOVA, discriminant analysis, Monte Carlo Simulation, and Multidimensional scaling among others. Regarding qualitative analysis techniques, case study $(n=5)$, grounded theory $(n=4)$, and ethnography $(n=2)$ account for 
the most common qualitative data analysis techniques used. Table 7 provides the top identified data analysis techniques.

Abstracts analysis also allowed us to identify 92 papers devoted to methodological issues. For example, Diamantopoulos et al (2012) analyze factors regarding the use of multi-item or single-item scales for construct measurement while Sorescu et al (2017) analyze the use of event study methodology on marketing research. Scale development papers account for 34 articles covering a wide range of constructs including value co-creation (Ranjan and Read 2016), brand personality appeal (Freling et al 2011), ethical work climate (Babin et al 2000), and attitude towards private labels products (Burton et al 1998).

Table 7. Top identified data analysis techniques

\begin{tabular}{clcc} 
Methodology & \multicolumn{1}{c}{ Data Analysis Technique } & \# Cases & $\mathbf{\%}$ \\
\hline & Structural Equation Modeling & 20 & $12,12 \%$ \\
& Meta-analysis & 20 & $12,12 \%$ \\
Bayesian Analysis & 7 & $4,24 \%$ \\
& Content analysis & 6 & $3,64 \%$ \\
& Regressions & 6 & $3,64 \%$ \\
& Cluster analysis & 6 & $3,64 \%$ \\
& Conjoint analysis & 6 & $3,64 \%$ \\
& Partial Least Squares & 5 & $3,03 \%$ \\
& Correlations & 5 & $3,03 \%$ \\
& Multitrait-Multimethod Matrix & 4 & $2,42 \%$ \\
& Path analysis & 4 & $2,42 \%$ \\
& Log-linear Models & 4 & $2,42 \%$ \\
& Miscellaneous & 59 & $35,76 \%$ \\
\hline \multirow{5}{*}{ Qualitative } & Case study & 5 & $3,03 \%$ \\
& Grounded Theory & 4 & $2,42 \%$ \\
& Ethnography & 2 & $1,21 \%$ \\
& Miscellaneous & 2 & $1,21 \%$ \\
\hline & & 165 & $100 \%$
\end{tabular}

\section{Conclusion}

This paper has shown the most cited articles published in JAMS throughout its history along with the institutions, author nationalities, and author collaborations. The paper has also shown, for the first time, how these articles reflect the main areas of research addressed by the journal. Key Marketing constructs were also identified, and data triangulation confirms the veracity of our analysis. Citation networks were examined from available metadata, and abstracts were analyzed using network analysis and text mining techniques. This analysis is supported in the paper by the use of data visualization tools and community detection algorithms.

The nine identified themes show the wide range of topics covered by JAMS during its 46 years of publication. These range from brand-related research to firms' performance, distribution channels, marketing communications, and corporate social responsibility. Moreover, abstract analysis reveals an objective common to all identified areas of research published in the journal; that is, the strategic contribution of all constructs studied to firms' 
performance. This is clear in areas such brand value creation and how this value contributes to brand equity, and firms' performance (Wang, Zhang, \& Ouyang, 2009). It is also clearly seen in the area of corporate social responsibility as a means to create value for stakeholders and how this value contributes to firms' value (Lenz, Wetzel, \& Hammerschmidt, 2017). Moreover, results from theme analysis using text mining is consistent with keyword analysis using Kumu's SLPA algorithm. In both cases, the three biggest themes or communities are brand strategic value (brand and value co-creation), firms' strategy and financial performance (firm capability and performance), and customer service (customer service). This suggests a "triad" of research domains that appear consistently in the journal. If $J A M S$ has had a singular research focus throughout its history, evidence from our paper shows that this is it. Moreover, our analysis shows that these research domains are highly focused on strategic issues to firms and seek to provide $J A M S$ readership with managerial implications that helps to improve firms' performance. Our analysis also provides evidence of $J A M S$ contribution to marketing theory building and methodological issues in the shape of both conceptual/theoretical papers and scale development papers.

One main limitation of this research is having analyzed only one journal. Although JAMS is a relevant journal within the marketing literature, future research should extend this analysis to other top-tier journals such as Journal of Marketing, Journal of Marketing Research, Journal of Consumer Research, and Marketing Science. Another limitation is that keywords analysis was limited to the 2003-2018 period due to unavailability of data from Scopus before this period. While various databases index author keywords similarly, we found that authorsubmitted keywords indexed by other journals (e.g. Web of Science or EBSCO) are not necessarily the same as those in Scopus. To avoid this data discrepancy, and maintain consistency, we focused on what was available in Scopus. 


\section{References}

Albrecht, C. M., Hattula, S., \& Lehmann, D. R. (2017). The relationship between consumer shopping stress and purchase abandonment in task-oriented and recreationoriented consumers. Journal of the Academy of Marketing Science, 45(5), 720-740.

Allen, A. M., Brady, M. K., Robinson, S. G., \& Voorhees, C. M. (2015). One firm's loss is another's gain: capitalizing on other firms' service failures. Journal of the Academy of Marketing Science, 43(5), 648-662.

Arunachalam, S., Ramaswami, S. N., Herrmann, P., \& Walker, D. (2018). Innovation pathway to profitability: the role of entrepreneurial orientation and marketing capabilities. Journal of the Academy of Marketing Science, 1-23.

Auh, S., Spyropoulou, S., Menguc, B., \& Uslu, A. (2014). When and how does sales team conflict affect sales team performance? Journal of the Academy of Marketing Science, 42(6), 658-679.

Bagozzi R.P., Gopinath M., Nyer P.U. (1999). The role of emotions in marketing. Journal of the Academy of Marketing Science, 27(2), 184-206.

Berry, L. L. (1995). Relationship marketing of services—growing interest, emerging perspectives. Journal of the Academy of Marketing Science, 23(4), 236-245.

Beverland, M. B., Wilner, S. J., \& Micheli, P. (2015). Reconciling the tension between consistency and relevance: design thinking as a mechanism for brand ambidexterity. Journal of the Academy of Marketing Science, 43(5), 589-609.

Blodgett, J. G., Lu, L. C., Rose, G. M., \& Vitell, S. J. (2001). Ethical sensitivity to stakeholder interests: A cross-cultural comparison. Journal of the Academy of Marketing Science, 29(2), 190-202.

Boles, J., \& Burton, S. (1992). An examination of free elicitation and response scale measures of feelings and judgments evoked by television advertisements. Journal of the Academy of Marketing Science, 20(3), 225-233.

Brasel, S. A., \& Gips, J. (2014). Enhancing television advertising: same-language subtitles can improve brand recall, verbal memory, and behavioral intent. Journal of the Academy of Marketing Science, 42(3), 322-336.

Calma, A., \& Davies, M. (2015). Studies in Higher Education 1976-2013: A Retrospective using Citation Network Analysis. Studies in Higher Education, 40(1), 4-21. http://dx.doi.org/10.1080/03075079.2014.977858

Calma, A., \& Davies, M. (2017). Geographies of Influence: A Citation Network Analysis of Higher Education 1972-2014. Scientometrics, 110(3), 1579-1599. Doi:10.1007/s11192$\underline{016-2228-3}$

Cavusgil, S. T., \& Cavusgil, E. (2012). Reflections on international marketing: destructive regeneration and multinational firms. Journal of the Academy of Marketing Science, 40(2), 202-217. 
Chen, D., Fu, Y., \& Shang, M. (2009). A fast and efficient heuristic algorithm for detecting community structures in complex networks. Physica A: Statistical Mechanics And Its Applications, 3882741-2749. doi:10.1016/j.physa.2009.03.022

Clarivate Analytics (2018). InCites Journal Citation Reports: Journal of the Academy of Marketing Science. Retrieved 25 June 2018, from http://jcr.incites.thomsonreuters.com.ezp.lib.unimelb.edu.au.

Cohen, J. A. (1960). A coefficient of agreement for nominal scales. Educational and Psychological Measurement, 20, 37-46.

Cron, W. L., Baldauf, A., Leigh, T. W., \& Grossenbacher, S. (2014). The strategic role of the sales force: Perceptions of senior sales executives. Journal of the Academy of Marketing Science, 42(5), 471-489.

Davies, M., \& Calma, A. (2016). Academy of Management Journal 1958-2014: A Citation Analysis. Scientometrics, 108(2), 959-975. doi: $\underline{10.1007 / \mathrm{s} 11192-016-1998-\mathrm{y}}$

Davies, M., \& Calma, A. (2017). Getting Cited: A Reconsideration of Purpose. Australian Universities' Review, 59(1), 69-75.

Davies, M., \& Calma, A. (2018). Australasian Journal of Philosophy 1947-2016: a retrospective using citation and social network analyses. Global Intellectual History. https://doi.org/10.1080/23801883.2018.1478233

Eisend, M., \& Küster, F. (2011). The effectiveness of publicity versus advertising: A metaanalytic investigation of its moderators. Journal of the Academy of Marketing Science, 39(6), 906-921.

Esper, T. L., Ellinger, A. E., Stank, T. P., Flint, D. J., \& Moon, M. (2010). Demand and supply integration: a conceptual framework of value creation through knowledge management. Journal of the Academy of marketing Science, 38(1), 5-18.

Guidry, J. A., Hollier, B. G., Johnson, L., Tanner, J. R., \& Veltsos, C. (2004). Surveying the cites: a ranking of marketing journals using citation analysis. Marketing Education Review, 14(1), 0-59.

Harmeling, C. M., Moffett, J. W., Arnold, M. J., \& Carlson, B. D. (2017). Toward a theory of customer engagement marketing. Journal of the Academy of Marketing Science, 45(3), 312-335.

Hogreve, J., Bilstein, N., \& Mandl, L. (2017). Unveiling the recovery time zone of tolerance: when time matters in service recovery. Journal of the Academy of Marketing Science, 45(6), 866-883.

Hollebeek, L. D., Srivastava, R. K., \& Chen, T. (2016). SD logic-informed customer engagement: integrative framework, revised fundamental propositions, and application to CRM. Journal of the Academy of Marketing Science, 1-25.

Homburg, C., Bornemann, T., \& Kretzer, M. (2014). Delusive perception—antecedents and consequences of salespeople's misperception of customer commitment. Journal of the Academy of Marketing Science, 42(2), 137-153. 
Hsu, L., Fournier, S., \& Srinivasan, S. (2016). Brand architecture strategy and firm value: how leveraging, separating, and distancing the corporate brand affects risk and returns. Journal of the Academy of Marketing Science, 44(2), 261-280.

Hult, G. T. M. (2015). JAMS 2010-2015: Literature themes and intellectual structure. Journal of the Academy of Marketing Science, 43, 663-669.

Hult, G. T. M., \& Ferrell, O. C. (2012). A tribute to forty years of top-level marketing research, Journal of the Academy of Marketing Science, 40, 1-7.

Hult, G. T. M., Neese, W. T., \& Bashaw, R. E. (1997). Faculty perceptions of marketing journals. Journal of Marketing Education, 19(1), 37-52.

Hult, G. T. M., Reimann, M., \& Schilke, O. (2009). Worldwide faculty perceptions of marketing journals: Rankings, trends, comparisons, and segmentations. globalEDGE Business Review, 3(3), 1-23.

Johnston, W. J., Le, A. N. H., \& Cheng, J. M. S. (2017). A meta-analytic review of influence strategies in marketing channel relationships. Journal of the Academy of Marketing Science, 1-29.

Kamakura, W. A., Ramón-Jerónimo, M. A., \& Gravel, J. D. V. (2012). A dynamic perspective to the internationalization of small-medium enterprises. Journal of the Academy of Marketing Science, 40(2), 236-251.

Kostoff, R. N., Toothman, D. R., Eberhart, H. J., \& Humenik, J. A. (2001). Text mining using database tomography and bibliometrics: A review. Technological Forecasting and Social Change, 68(3), 223-253.

Kukar-Kinney, M., \& Close, A. G. (2010). The determinants of consumers' online shopping cart abandonment. Journal of the Academy of Marketing Science, 38(2), 240250.

Kumar, V., Rajan, B., Gupta, S., \& Dalla Pozza, I. (2017). Customer engagement in service. Journal of the Academy of Marketing Science, 1-23.

LaFleur, E. K., Reidenbach, R. E., Robin, D. P., \& Forrest, P. J. (1995). An exploration of rule configuration effects on the ethical decision processes of advertising professionals. Journal of the Academy of Marketing Science, 24(1), 66-76.

Lam S.Y., Shankar V., Erramilli M.K., \& Murthy B. (2004). Customer value, satisfaction, loyalty, and switching costs: An illustration from a business-to-business service context. Journal of the Academy of Marketing Science, 32(3), 293-311.

Landis, J.R. \& Koch, G.G. (1977). The measurement of observer agreement for categorical data. Biometrics, 33, 159-174.

Leeflang, P. S., \& Parreño-Selva, J. (2012). Cross-category demand effects of price promotions. Journal of the Academy of Marketing Science, 40(4), 572-586.

Lehmann, D. R. (2005). Journal evolution and the development of marketing. Journal of Public Policy \& Marketing, 24(1), 137-142. 
Lenz, I., Wetzel, H. A., \& Hammerschmidt, M. (2017). Can doing good lead to doing poorly? Firm value implications of CSR in the face of CSI. Journal of the Academy of Marketing Science, 45(5), 677-697.

Li, S., Sivadas, E., \& Johnson, M. (2015). Explaining article influence: capturing article citability and its dynamic effects. Journal Of The Academy Of Marketing Science, 43(1), 52-72. doi:10.1007/s11747-014-0392-7

Lim, E. A. C., Lee, Y. H., \& Foo, M. D. (2017). Frontline employees' nonverbal cues in service encounters: a double-edged sword. Journal of the Academy of Marketing Science, 45(5), 657-676.

Liu, X., \& Murata, T. (2009). Advanced modularity-specialized label propagation algorithm for detecting communities in networks. Physica A: Statistical Mechanics and its Applications, 389(7), 1493-150. doi:10.1016/j.physa.2009.12.019

Luke, R. H., \& Doke, E. R. (1987). Marketing journal hierarchies: Faculty perceptions, 1986-1987. Journal of the Academy of Marketing Science, 15(1), 74-78.

Luo X., Wieseke J., Homburg C. (2012). Incentivizing CEOs to build customer- and employee-firm relations for higher customer satisfaction and firm value. Journal of the Academy of Marketing Science, 40(6), 745-758.

Lusch, R. F., Vargo, S. L., \& Tanniru, M. (2010). Service, value networks and learning. Journal of the academy of marketing science, 38(1), 19-31.

Madden T.J., Fehle F., Fournier S. (2006). Brands matter: An empirical demonstration of the creation of shareholder value through branding. Journal of the Academy of Marketing Science, 34(2), 224-235.

Mahar, S., Wright, P. D., Bretthauer, K. M., \& Hill, R. P. (2014). Optimizing marketer costs and consumer benefits across "clicks" and "bricks". Journal of the Academy of Marketing Science, 42(6), 619-641.

Malhotra, N. K. (1996). The impact of the Academy of Marketing Science on marketing scholarship: An analysis of the research published in JAMS. Journal of the Academy of Marketing Science, 24(4), 291-298.

Martin, K. D., Johnson, J. L., \& French, J. J. (2011). Institutional pressures and marketing ethics initiatives: the focal role of organizational identity. Journal of the Academy of Marketing Science, 39(4), 574-591.

Mazodier, M., \& Rezaee, A. (2013). Are sponsorship announcements good news for the shareholders? Evidence from international stock exchanges. Journal of the Academy of Marketing Science, 41(5), 586-600.

Meyer-Waarden, L., \& Benavent, C. (2009). Grocery retail loyalty program effects: selfselection or purchase behavior change?. Journal of the Academy of Marketing Science, 37(3), 345-358.

Miniard, P. W., Jayanti, R. K., Alvarez, C. M., \& Dickson, P. R. (2018). What brand extensions need to fully benefit from their parental heritage. Journal of the Academy of Marketing Science, 1-16. 
Morgan, N. A., Katsikeas, C. S., \& Vorhies, D. W. (2012). Export marketing strategy implementation, export marketing capabilities, and export venture performance. Journal of the Academy of Marketing Science, 40(2), 271-289.

Nakata, C., \& Sivakumar, K. (2001). Instituting the marketing concept in a multinational setting: The role of national culture. Journal of the Academy of Marketing Science, 29(3), 255-276.

Nikolaeva, R., \& Bicho, M. (2011). The role of institutional and reputational factors in the voluntary adoption of corporate social responsibility reporting standards. Journal of the Academy of Marketing Science, 39(1), 136-157.

Olson, E. L., \& Thjømøe, H. M. (2009). Sponsorship effect metric: assessing the financial value of sponsoring by comparisons to television advertising. Journal of the Academy of Marketing Science, 37(4), 504.

Parker, J. R., Lehmann, D. R., Keller, K. L., \& Schleicher, M. G. (2018). Building a multicategory brand: when should distant brand extensions be introduced?. Journal of the Academy of Marketing Science, 46(2), 300-316.

Peloza, J., \& Shang, J. (2011). How can corporate social responsibility activities create value for stakeholders? A systematic review. Journal of the academy of Marketing Science, 39(1), 117-135.

Rasoulian, S., Grégoire, Y., Legoux, R., \& Sénécal, S. (2017). Service crisis recovery and firm performance: insights from information breach announcements. Journal of the Academy of Marketing Science, 45(6), 789-806.

Samiee, S., \& Chabowski, B. R. (2012). Knowledge structure in international marketing: A multi-method bibliographic analysis. Journal of the Academy of Marketing Science, 40, 364-386.

Scheer, L. K., Miao, C. F., \& Palmatier, R. W. (2015). Dependence and interdependence in marketing relationships: Meta-analytic insights. Journal of the Academy of Marketing Science, 43(6), 694-712.

Scimago Lab (2018). Scimago Journal and Country Rank: Journal of the Academy of Marketing Science. Retrieved 25 June 2018, from https://www.scimagojr.com.

Seggie, S. H., \& Griffith, D. A. (2009). What does it take to get promoted in marketing academia? Understanding exceptional publication productivity in the leading marketing journals. Journal of Marketing, 73(January), 122-132.

Sen, S., Bhattacharya, C. B., \& Korschun, D. (2006). The role of corporate social responsibility in strengthening multiple stakeholder relationships: A field experiment. Journal of the Academy of Marketing science, 34(2), 158-166.

Shannahan, K. L., Bush, A. J., \& Shannahan, R. J. (2013). Are your salespeople coachable? How salesperson coachability, trait competitiveness, and transformational leadership enhance sales performance. Journal of the Academy of Marketing Science, 41(1), 40-54. 
Sheng, S., Zhou, K. Z., Li, J. J., \& Guo, Z. (2018). Institutions and opportunism in buyersupplier exchanges: the moderated mediating effects of contractual and relational governance. Journal of the Academy of Marketing Science, 1-18.

Smith, N. C. (2009). Bounded goodness: marketing implications of Drucker on corporate responsibility. Journal of the Academy of Marketing Science, 37(1), 73-84.

Song, R., Moon, S., Chen, H. A., \& Houston, M. B. (2018). When marketing strategy meets culture: the role of culture in product evaluations. Journal of the Academy of Marketing Science, 46(3), 384-402.

Sridhar, S., Narayanan, S., \& Srinivasan, R. (2014). Dynamic relationships among R\&D, advertising, inventory and firm performance. Journal of the Academy of Marketing Science, 42(3), 277-290.

Swoboda, B., Puchert, C., \& Morschett, D. (2016). Explaining the differing effects of corporate reputation across nations: a multilevel analysis. Journal of the Academy of Marketing Science, 44(4), 454-473.

Szymanski D.M., Henard D.H. (2001). Customer satisfaction: A meta-analysis of the empirical evidence. Journal of the Academy of Marketing Science, 29(1), 16-35.

Touzani, M., \& Moussa, S. (2010). Ranking Marketing Journals Using the Search Engine Google Scholar. Marketing Education Review, 20(3), 229. doi:10.2753/MER10528008200304

van der Borgh, M., \& Schepers, J. (2017). Are conservative approaches to new product selling a blessing in disguise?. Journal of the Academy of Marketing Science, 1-22.

Varadarajan, R. (2017). Innovating for sustainability: a framework for sustainable innovations and a model of sustainable innovations orientation. Journal of the Academy of Marketing Science, 45(1), 14-36.

Vargo S.L., Lusch R.F. (2008). Service-dominant logic: Continuing the evolution. Journal of the Academy of Marketing Science, 36(1), 1-10.

Wang, F., Zhang, X. P. S., \& Ouyang, M. (2009). Does advertising create sustained firm value? The capitalization of brand intangible. Journal of the Academy of Marketing Science, 37(2), 130-143.

Weerawardena, J., Mort, G. S., Salunke, S., Knight, G., \& Liesch, P. W. (2015). The role of the market sub-system and the socio-technical sub-system in innovation and firm performance: a dynamic capabilities approach. Journal of the Academy of Marketing Science, 43(2), 221-239.

Wu, Q., Luo, X., Slotegraaf, R. J., \& Aspara, J. (2015). Sleeping with competitors: the impact of NPD phases on stock market reactions to horizontal collaboration. Journal of the Academy of Marketing Science, 43(4), 490-511.

Xie, C., Bagozzi, R. P., \& Grønhaug, K. (2015). The role of moral emotions and individual differences in consumer responses to corporate green and non-green actions. Journal of the Academy of Marketing Science, 43(3), 333-356. 
Xie, J., Kelley, S., and Szymanski, B. K. (2013). Overlapping Community Detection in Networks: the State of the Art and Comparative Study. ACM Computing Surveys, 45(4), 1-37.

Xie, J., Szymanski, B. K., Liu, X. (2011). SLPA: Uncovering Overlapping Communities in Social Networks via a Speaker-listener Interaction Dynamic Process. 2011 11th IEEE International Conference on Data Mining Workshops, 11 December 2011, Vancouver BC Canada.

Yoo B., Donthu N., Lee S. (2000). An examination of selected marketing mix elements and brand equity. Journal of the Academy of Marketing Science, 28(2), 195-211.

Yoon, B., \& Park, Y. (2004). A text-mining-based patent network: Analytical tool for hightechnology trend. Journal of High Technology Management Research, 15(1), 37-50.

Zielke, S., \& Komor, M. (2015). Cross-national differences in price-role orientation and their impact on retail markets. Journal of the Academy of Marketing Science, 43(2), 159180. 